\title{
Potential therapeutic targets for growth arrest of colorectal cancer cells exposed to PTHrP
}

\author{
María Julia Martín ${ }^{\mathrm{a}}$, Graciela Gigola ${ }^{\mathrm{b}}$, Ariel Zwenger ${ }^{\mathrm{c}}$, Martín Carriquiriborde ${ }^{\mathrm{d}}$, Florencia Gentil ${ }^{\mathrm{d}}$, \\ Claudia Gentilia,* \\ ${ }^{a}$ Instituto de Ciencias Biológicas y Biomédicas del Sur (INBIOSUR), Dept. Biología Bioquímica y Farmacia, Universidad Nacional del Sur-CONICET, Bahía Blanca, \\ Argentina \\ ${ }^{\mathrm{b}}$ Dept. Biología Bioquímica y Farmacia, Universidad Nacional del Sur, Bahía Blanca, Argentina \\ ${ }^{\mathrm{c}}$ Dept. de Oncología, Hospital Provincial de Neuquén, Neuquén, Argentina

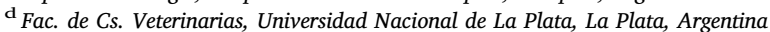

\section{A R T I C L E I N F O}

\section{Keywords:}

PTHrP

Colorectal cancer

Molecular mechanisms

Mitogenic signaling

Chemoresistance

\begin{abstract}
A B S T R A C T
Although PTHrP is implicated in several cancers, its role in chemoresistance is not fully elucidated. We found that in CRC cells, PTHrP exerts proliferative and protective effects and induces cell migration. The aim of this work was to further study the effects of PTHrP in CRC cells. Herein we evidenced, for the first time, that PTHrP induces resistance to CPT-11 in Caco-2 and HCT116 cells; although both cell lines responded to the drug through different molecular mechanisms, the chemoresistance by PTHrP in these models is mediated through ERK, which in turn is activated by PCK, Src and Akt. Moreover, continue administration of PTHrP in nude mice xenografts increased the protein levels of this MAPK and of other markers related to tumorigenic events. The understanding of the molecular mechanisms leading to ERK $1 / 2$ activation and the study of ERK targets may facilitate the development of new therapeutic strategies for CRC treatment.
\end{abstract}

\section{Introduction}

The parathyroid hormone-related protein (PTHrP) was found to be secreted from various tumors and responsible for the hypercalcemia of malignancy, being this a bad prognostic sign in malignancies (Kir et al., 2014). However, it has been widely studied that this hormone is distributed in most fetal and adult tissues and has an important role in fetus development and adult tissues homeostasis (Wysolmerski and Stewart, 1998; Malakouti et al., 1996; Sidler et al., 1996; Kovacs, 2015). Today, it is recognized for its endocrine, paracrine and autocrine modes of action (Maioli and Fortino, 2004; McCauley and Martin, 2012). In gut mucosal epithelium, it has been reported that PTHrP and PTHrP receptor genes are widespread expressed suggesting that the peptide exerts a local regulatory role via an autocrine/paracrine pathway (Li et al., 1995; Watson et al., 2000). Full-length PTHrP undergoes posttranslational processing, which gives rise to a family of mature secretory peptides. PTHrP (1-34) with the $\mathrm{N}$-terminal region is capable of binding to the PTH/PTHrP receptor (PTH1R, which is a G protein-coupled receptor), because this peptide is highly homologous with PTH (1-34), whereas midregion and C-terminal peptides exert their effects through uncharacterized receptors (Wysolmerski, 2012).
Cytosolic PTHrP can also use a bipartite multibasic nuclear localization signal to translocate to the nucleus and act through an intracrine pathway (McCauley and Martin, 2012). PTHrP was found to be expressed in numerous types of cancer (McCauley and Martin, 2012) and in more than $90 \%$ of colorectal cancer (CRC) patients (Soki et al., 2012). Several studies have shown that PTHrP levels are higher in less differentiated colorectal adenocarcinomas than in those with greater degree of differentiation and that its expression correlates with the severity of colon carcinoma, specifically, with the differentiation, depth of invasion, lymphatic invasion, lymph node metastasis, and hepatic metastases (Malakouti et al., 1996; Nishihara et al., 1999, 2007).

$\mathrm{CRC}$ is one of the major causes of cancer death worldwide (Siegel et al., 2015); although this disease can be cured at early stages, patients frequently present metastases at the time-point of the occurrence of symptoms and diagnosis, leading to a high mortality rate (Arnold et al., 2017). Moreover, most people with metastatic CRC will eventually present clinical failure (i.e. disease recurrence or progression) or lack of response to first-line treatment, thus becoming potential candidates for second-line systemic therapy. The availability of Irinotecan (CPT-11, a topoisomerase I inhibitor, targets the topoisomerase of tumor cells in Sphase of cell cycle) has radically altered both first- and second-line

\footnotetext{
* Corresponding author. Dept. Biología, Bioquímica y Farmacia-INBIOSUR, Universidad Nacional del Sur, San Juan 670, 8000, Bahía Blanca, Argentina.

E-mail address: cgentili@criba.edu.ar (C. Gentili).
} 
treatment of advanced CRC compared with the era in which the sole treatment option in advanced disease was 5-fluorouracil (5-FU) (Guglielmi and Sobrero, 2007). Moreover, the therapy with CPT-11based combinations showed better overall survival, increased the overall tumor response rate and improved life quality in patients respect to the therapy with the drug alone (Mocellin et al., 2017). Despite these available drugs, chemoresistance is a frequent cause of treatment failure in patients with CRC. It is known that PTHrP can mediate chemoresistance in tumor cell lines derived from prostate and osteosarcoma (Cui et al., 2016; Gagiannis et al., 2009); however, to the present it is unknown whether PTHrP confers chemoresistance to CRC cells.

Significant advances have been made in understanding the biology of CRC and the underlying mechanisms related to the tumorigenesis of this disease to facilitate new approaches for its diagnosis and therapy. It is known that several mitogenic signaling pathways play key roles in maintaining the growth and proliferation of CRC. Activation of ERK1/2 MAPK signaling is very common in CRC (Cheruku et al., 2015); it has been reported that MEK/ERK signaling contributes to 5-FU resistance and supports CRC cell growth (Yang et al., 2016a) whereas small molecular inhibitors targeting ERK signaling have shown anti-tumor effects on the colon cancer (Peng et al., 2013). Like MAPKs, there is increasing evidence that the activation of PI3K/Akt pathway is associated with CRC, and can convert differentiated human gastric or colonic mucosa to a less differentiated and more malignant phenotype. Akt is probably the main kinase that mediate the effects of PI3K on tumor growth and progression (Pandurangan, 2013). Akt is overexpressed in colon cancer, and its phosphorylation in this disease correlates with cell proliferation and inhibition of apoptosis, as well as different clinic-pathological parameters such as invasive grade, vessel infiltration, lymph node metastasis, tumor stage and chemoresistance (Khaleghpour, 2004; Tan et al., 2017).

A regulator of both, PI3K/Akt and MAPKs signaling pathways is Src, which is a non-receptor protein tyrosine kinase. Since $80 \%$ of patients with CRC shows a deregulation of Src expression and this fact is related with metastasis and drug resistance, therefore, the inhibition of Src may be useful for the treatment of CRC (Chen et al., 2014). The members of PKC family are also modulators of PI3K and MAPKs pathways. These serine/threonine kinases are classified into three subfamilies and they are involved in multiple cell responses; for this reason, PKC isozymes can act as therapeutic targets for several diseases. Further, significant work has also explored the activation, mechanism, and function of PKC isozymes in the development and progression of multiple types of cancer (Kang, 2014).

Different cell models play an important role in understanding cellular events related to pathophysiological conditions in human CRC because it is a heterogeneous disease with three different, but partly overlapping, molecular phenotypes reflecting different forms of DNA instability (Ahmed et al., 2013). Caco-2 cells are derived from a human colon adenocarcinoma, and they differentiate spontaneously in vitro under standard culture conditions thereby exhibiting enterocyte-like structural and functional characteristics. The human colon carcinoma cell line HCT116, another CRC derived cell line, shows a more aggressive phenotype due to hyperactivating mutations in KRAS and PIK3CA genes (Ahmed et al., 2013; Botchkina et al., 2009). We previously showed that in both, Caco-2 cells and HCT116 cells, PTH1R is expressed and that exogenous PTHrP modulates cell cycle progression and exerts proliferative and protective effects via MAPKs and PI3-kinase/Akt signaling pathways (Calvo et al., 2014; Lezcano et al., 2013; Martín et al., 2014). More recently, we obtained evidence that in both cell lines PTHrP induces cell migration via RSK/ERK1/2 signaling pathway but not through $\mathrm{p} 38$ MAPK; also the peptide increases the expression of the active form of RSK in HCT116 tumor xenografts (Calvo et al., 2017). In view of the effects of PTHrP in vivo, the first objective of this work was to evaluate whether the hormone modulates the expression of other molecular markers related to tumorigenic events in CRC tumor xenografts. The next objective of this work was to investigate the upstream pathways that modulate the mitogenic cascades activated in response to PTHrP treatment in two CRC cell lines with phenotypic differences (Caco-2 cells and HCT116 cells) with the aim to also evaluate whether these molecular mechanisms are similar or different in these two types of tumor intestinal cells. Finally, the third objective was to study if cell exposure to PTHrP modify the cytotoxicity induced by CPT-11 and if so, to assess if the combination of CPT-11 with specific inhibitors of the signaling pathways that mediate the response of tumor intestinal cells to PTHrP reestablishes the effects of the chemotherapeutic agent in both cell lines.

\section{Materials and methods}

\subsection{Reagents and antibodies}

Human PTHrP (1-34) and Trypan Blue dye were obtained from Sigma-Aldrich Chemical Co (St. Louis, Missouri, USA). Antibodies were purchased from the following sources: anti-ERK 1/2 MAPK was from abcam (Cambridge, MA, USA); anti-phospho CREB/ATF-1, anti-Cyclin D1, anti-phospho p44/42 (phospho ERK 1/2), anti-phosphoAkt, antiphosphoSrc (Tyr416), anti-p27 and anti-c-Myc were provided by Cell Signaling Technology (Beverly, Massachusetts, USA); anti-Ki67 antibody was from bioSB (Santa Barbara, CA, USA); anti-PTH1R receptor antibody was from BABCO (Richmond, CA); Anti-PCKa, anti-Src, antiPARP, anti-Bcl-2, anti-Akt, anti-GAPDH, goat anti-rabbit peroxidase conjugated secondary antibody and goat anti-mouse peroxidase conjugated secondary antibody were from Santa Cruz Biotechnology (Santa Cruz, California, USA). PD 98059, Ro-318220 and PP1 were obtained from Calbiochem (San Diego, California, USA). GSK690693 was from Santa Cruz Biotechnology (Santa Cruz, California, USA). Protein size markers were from Amersham Biosciences (Piscataway, New Jersey, USA), PVDF (Immobilonpolyvinylidene difluoride) membranes and ECL chemiluminescence detection kit were from Amersham (Little Chalfont, Buckinghamshire, England). CPT-11 was gently provided by Dr. Ariel Zwenger. All other used reagents were of analytical grade.

\subsection{Xenografts in nude mice}

Nude mice xenografts of HCT116 cells were established to investigate PTHrP effects in vivo since it has been shown that these cells are tumorigenic in nude mice being its tumorigenic capacity much greater than that of Caco-2 cells (McIntyre et al., 2015; Tong et al., 2011). $1 \times 10^{6}$ HCT116 cells were subcutaneously injected into the left dorsal flanks of 6-week-old male LAE:NIH (S)-Fox $1^{\text {nu }}$ mice. We refer this mice strain as "nude". Four days after inoculation, animals were randomized (blindly) into control and treatment groups ( $n=6 /$ group). Mice were administered daily with PTHrP (40 $\mu \mathrm{g} / \mathrm{kg}$ in $100 \mathrm{ul} \mathrm{PBS),} \mathrm{or}$ an equal volume of vehicle solution, as control, by intratumoral injection (2 groups in total; each group represents an experimental unit). We selected this dose of the peptide based in previous studies performed by us and by other investigators with PTH and/or PTHrP in rodents (Frolik et al., 1999; Stewart et al., 2000; Zhou et al., 2003; Calvo et al., 2017). The mice were sacrificed and tumors were removed and weighted after 20 days of PTHrP treatment. Tumor size was calculated according to the following formula: tumor volume $\left(\mathrm{mm}^{3}\right)=$ tumor width $\left(\mathrm{mm}^{2}\right) \mathrm{x}$ tumor length (mm)/2 (Wang et al., 2002). At the end of the trial the average weights were $0.30 \mathrm{~g} \pm 0.11$ (standard deviation) and $0.4 \mathrm{~g} \pm 0.10$ (standard deviation) for control tumors and treated tumors, respectively whereas the average volumes were $0.21 \mathrm{~mm}^{3} \pm 0.08$ (standard deviation) and $0.26 \mathrm{~mm}^{3} \pm 0.08$ (standard deviation) for control tumors and treated tumors. Tumor tissue was fixed with $4 \%$ neutral buffered formaldehyde solution for immunohistochemistry assay. All experiments with animals were approved by a local animal committee for ethics (CICUAE-UNS) and were carried out in accordance with the National Institutes of Health guide for the care and use of Laboratory 
animals (NIH, 1996).

\subsection{Immunohistochemistry}

Paraffin embedded sections were deparaffinised, re-hydrated and pre-treated using heat mediated antigen retrieval (using a pressure cooker) with sodium citrate buffer ( $10 \mathrm{mM}, \mathrm{pH} 6)$ for $15 \mathrm{~min}$. After the antigen retrieval step, tissue sections were washed and blocked in $30 \%$ $\mathrm{H}_{2} \mathrm{O}_{2}$, and the primary antibodies (anti-phospho CREB/ATF-1, antiphospho ERK, anti-ERK 1/2, anti-Cyclin D1 and anti-phospho Akt) were added for overnight incubations at $4{ }^{\circ} \mathrm{C}$. Immunohistochemical staining was carried out manually using ABCAM Detection IHC Kit (abcam, Cambridge, MA, USA) according to the manufacturer's instructions. Finally, the slides were monitored under microscope and the reaction was stopped with distilled water, counterstained with hematoxylin, dehydrated, and coverslipped. Staining was visualized using a light microscope.

\subsection{Staining assessment and scoring}

Phospho-ERK 1/2, ERK 1/2, phospho-Akt, Cyclin D1 and phosphoCREB/ATF-1 expression levels were classified semi-quantitatively based on the total combined scores of the percentage of positively stained tumor cells together with the staining intensity. A tumor was scored as ' 0 ' if $<5 \%$ of tumor cells were stained positive, ' 1 ' if $5-50 \%$ were stained positive, ' 2 ' if $>50-90 \%$ of the cells were stained positive and ' 3 ' if the $90-100 \%$ of cells were stained positive. The staining intensity was scored as ' 0 ' if no staining of cells occurred or if there was only weak staining, ' 1 ' if there was moderate staining and ' 2 ' in cases of strong staining. The final score of all proteins expression was defined as 'low protein expression' if the sum of the positivity score and the staining intensity score was $0-1$, 'middle protein expression' if the sum was 2-3 and 'high protein expression' if the sum was 4-5 (Allen, 2006; Yang et al., 2010). In each case, at least three different tumor areas were evaluated and the mean of the results was taken as the final expression score. The scoring procedure was carried out twice by two independent pathologists who had no knowledge of the data and corresponding hematoxylin and slides. The concordance rate between the two pathologists was $>95 \%$.

\subsection{Determination of proliferative index}

The proliferative indices in untreated and treated tumors were determined by staining tumor sections with an anti-Ki67 antibody, as previously described (Terraneo et al., 2013). To determine the index in both tumors, positive and total nuclei were quantified in five random microscopic areas at $40 \times$ by two independent observers with $100 \%$ agreement in their observations. Weak and strong nuclear labeling was considered positive. Both indices were expressed as a percentage of stained cells to total cells.

\subsection{Cell culture and treatment}

The human colorectal cell lines Caco-2 and HCT116 (from the American Type Culture Collection, Manassas, Virginia) were cultured at $37^{\circ} \mathrm{C}$ in DMEM (Sigma-Aldrich Chemical Co., St. Louis, Missouri, USA) containing 10\% FBS (Natocor, Córdoba, Argentina), 1\% non-essential acids, $100 \mathrm{UI} / \mathrm{mL}$ penicillin, $100 \mathrm{mg} / \mathrm{mL}$ streptomycin and $50 \mathrm{mg} / \mathrm{mL}$ gentamycin in a humid atmosphere of $5 \% \mathrm{CO}_{2}$ in air. Cultures were passaged every 2 days with fresh medium. All experiments were performed using passages less than 15. Experimental cultures were grown to $80 \%$ confluence in serum-containing medium, and then cells were serum-deprived $24 \mathrm{~h}$ before the addition of $10^{-8} \mathrm{M}$ PTHrP (1-34) at different times. This dose of exposure was selected because we previously studied the effects of PTHrP (1-34) $10^{-8} \mathrm{M}$ in Caco-2 cells and HCT116 cells expressing PTH/PTHrP receptor (Calvo et al., 2014;
Martín et al., 2014). In previous study we showed the relevance of exogenous PTHrP in the tumor intestinal cellular response since we observed that endogenous PTHrP (produced by the tumor cell) did not influence on cellular response (Martín et al., 2014). Where indicated, cells were pretreated for 30 min with Ro-318220 (an inhibitor of PKC), PD 98059 (an inhibitor of MEK, which is the upstream kinase of ERK1/ 2), PP1 (an inhibitor of Src) or GSK690693 (an inhibitor of Akt). Control conditions were performed by addition of an equivalent volume of DMSO (which is the vehicle of all used inhibitors). In previous works we confirmed the effectiveness of the kinases inhibitors PD 98059 and Ro-318220 (Calvo et al., 2011, 2014; Martín et al., 2014), whereas PP1 and GSK690693 doses were chosen according to previous works in vitro (Levy et al., 2009; Maat et al., 2009; Saksena et al., 2005).

\subsection{Measurement of CPT-11 effects}

CPT-11 cytotoxicity was assessed by Trypan blue dye exclusion test. Caco-2 and HCT116 cells were seeded in a 24-well plate until $80 \%$ confluence. Cells were treated with or without PTHrP $10^{-8} \mathrm{M}$ and/or CPT-11 $(10 \mu \mathrm{M})$ for triplicates for 5 days or 1 day, respectively. The dose of this drug was chosen according to previous works (Erdem et al., 2017; Maitra et al., 2014). Where indicated, both cell lines were preincubated with PD 98059, GSK690693 or the vehicle. After the treatment, cells were washed with PBS buffer, released from the cultured dish using trypsin-EDTA, incubated with $0.4 \%$ of Trypan Blue stain and counted in a Neubauer chamber observed in a microscope. Cells were counted per field and the number of cells that excluded the stain (viable cells) was determined in each condition.

\subsection{Western blot analysis}

Cells were washed with PBS buffer plus $25 \mathrm{mMNaF}$ and $1 \mathrm{mM}$ $\mathrm{Na}_{3} \mathrm{VO}_{4}$, and lysed in buffer containing 50 mMTris- $\mathrm{HCl}$ (pH 7.4), 150 mMNaCl, $3 \mathrm{mMKCl}, 1 \mathrm{mM}$ EDTA,1\% Tween-20, 1\% Nonidet P-40, $20 \mu \mathrm{g} / \mathrm{mL}$ aprotinin, $20 \mu \mathrm{g} / \mathrm{mL}$ leupeptin, $1 \mathrm{mMphenylmethylsulfonyl}$ fluoride (PMSF), $25 \mathrm{mMNaF}$, and $1 \mathrm{mM} \mathrm{Na}_{3} \mathrm{VO}_{4}$. The lysates were incubated on ice for $10 \mathrm{~min}$, vortexed for $45 \mathrm{~s}$, and maintained on ice for another $10 \mathrm{~min}$. After centrifugation at $14000 \mathrm{~g}$ and $4{ }^{\circ} \mathrm{C}$ for $15 \mathrm{~min}$, the supernatant was collected and proteins were quantified by the Bradford method. Lysate proteins dissolved in $5 \times$ Laemmli sample buffer were separated $(30 \mu \mathrm{g} / \mathrm{lane})$ using SDS-polyacrylamide gels (10\% acrylamide) and electrotransfered to PVDF membranes. After blocking with $5 \%$ nonfat milk in TBST buffer (50 mMTris pH 7.2-7.4, $200 \mathrm{mMNaCl}$, $0.1 \%$ Tween-20), the membranes were incubated overnight with the appropriate dilution of primary antibody in TBST with $1 \%$ nonfat milk. After washing, membranes were incubated with the appropriate dilution of horse radish peroxidase-conjugated secondary antibody in TBST with $1 \%$ non-fatmilk. Finally, the blots were developed by ECL with the use of Kodak BioMax Light film and digitalized with a GS-700 Imaging Densitomer (Bio-Rad, Hercules, California,USA).

\subsection{Stripping and reproving membranes}

The complete removal of primary and secondary antibodies from the membraes was achieved by incubating the membranes in stripping buffer (62.5 mMTris- $\mathrm{HCl} \mathrm{pH} 6.8,2 \%$ SDS and $50 \mathrm{mM} \beta$-mercaptoethanol) at $55{ }^{\circ} \mathrm{C}$ for $30 \mathrm{~min}$ with agitation. Then, membranes were washed for $10 \mathrm{~min}$ in TBST (1\% Tween-20) and blocked, as indicated above, for $1 \mathrm{~h}$ at room temperature. After that, membranes were ready to reprove with the corresponding antibodies.

\subsection{Statistical analysis}

Data obtained from three in vitro independent experiments performed in triplicate were presented as mean \pm SD. Student's t-test (two-tailed, equal variance) was used to determine significant 
differences between two groups of data. p values of $<0.05$ and $<0.01$ were considered as statistically significant, and are indicated by asterisks (* and **, respectively) or hash symbol (\# and \#\#, respectively).

\section{Results}

3.1. PTHrP modulates molecular mechanisms related to tumorigenic events in nude mice tumor xenografts

RSK signaling is involved in many cancers, controls oncogenic processes through the regulation of transcription factors and/or cellular modulators. Theses kinases also regulate protein synthesis, and therefore, RSK-mediated translational control may play a critical role in the regulation of tumorigenic cellular events (Park and Cho, 2012). Recently, we obtained evidence that PTHrP induces the activation of RSK in HCT116 tumor xenografts. Since in vitro the peptide activates RSK via ERK1/2 signaling pathway but not through p38 MAPK in HCT116 cell line (Calvo et al., 2017), therefore our first objective was to investigate whether the hormone also modulates the expression of other molecular markers related to tumorigenic events (such as MAPKs) in CRC tumor tissues. Immunohistochemistry analysis of these tumor xenografts showed increased immunoreactivity scores of active ERK $1 / 2$ and total ERK 1/2 in tumors treated with PTHrP respect to the levels observed in tumor treated with PBS, which is the vehicle of the hormone (Fig. 1a and $b$ left and right panels). PTHrP treatment did not change the protein levels of the active form of Akt (Fig. 1c). As in vitro we previously obtained evidence that PTHrP increases the protein expression of Cyclin D1, a positive cell cycle regulator, and also induces CREB and ATF phosphorylation, two transcription factors that play important roles in the regulation of cell proliferation through MAPK pathways (Martín et al., 2014), then we evaluated the protein levels of Cyclin D1 and phospho-CREB/ATF-1 in HCT116 xenografts treated or untreated with PTHrP. Representative immunohistochemical staining shown in Fig. 1d and e (left and right panels) revealed that the hormone increased the immunoreactivity score of Cyclin D1 and active CREB/ATF-1 and as expected, the localization of all transcription factors evaluated was nuclear whereas active and total ERK 1/2 MAPKs and Akt were observed in the cytoplasm and nucleus of HCT116 cells. To provide additional evidence of the role of PTHrP as a regulator of tumor proliferation markers expression in vivo, we also evaluate the level of Ki67, which is a nuclear protein expressed in proliferating cells and is a marker for cell proliferation of solid tumors. Based on the immunostained cells, we then obtained the proliferation index, expressed in percentage, from untreated and treated tumors. As shown in Fig. 1f, PTHrP increased the protein levels of Ki67 whereas the proliferation index was significantly greater in treated tumors than in non-treated tumors.

\subsection{PTHrP induces the phosphorylation and activation of Src kinase in Caco-2 cells and HCT116 cells}

The activation of ERK1/2 signaling is very common in colon cancer and is vital for the growth of CRC cells (Cheruku et al., 2015; Setia et al., 2014), We previously observed that PTHrP stimulates cell proliferation and cell cycle progression through ERK MAPK in tumor intestinal cells (Martín et al., 2014; Calvo et al., 2014). Moreover, our recent studies revealed that PTHrP can promote cell migration through RSK/ERK MAPK in Caco-2 cells and HCT116 cells (Calvo et al., 2017). Since we also detected ERK activation in vivo, then our next goal was to investigate signal transduction pathways through which PTHrP triggers ERK 1/2 MAPK activation in Caco-2 cells and HCT116 cells.

It has been reported that stimulation of the Ras/Raf/MEK/ERK cascade can occur by activation of the Src kinase (McCubrey et al., 2007). Furthermore, increased Src activity has been found in many cancers, including colon cancer (Steeg, 2016). To evaluate whether Src is part of the PTHrP signaling mechanism in tumor intestinal cells, we first monitored Tyr416 phosphorylation state of c-Src because in this enzyme, autophosphorylation in its kinase domain at Tyr416 alters its conformation and increases its intrinsic kinase activity (Chen et al., 2014). Caco-2 cells and HCT116 cells were exposed to PTHrP for the times indicated in Fig. 2a and Fig. $2 \mathrm{~b}$ followed by Western blot analysis of cell lysates with anti-c-Src-phospho Tyr416. As shown in Fig. 2a (left panel) and 2b (left panel), PTHrP transiently increases the phosphorylation on Tyr416 of c-Src, with maximal effects at $60-120 \mathrm{~min}$ and at 1-3 min for Caco-2 cells and HCT116 cells, respectively. Immunoblot analysis using an anti-Src antibody revealed that the protein levels of total Src were no different in the absence or presence of PTHrP at the times indicated, demonstrating a true increase in the phosphorylation status of Src (Fig. 2a and b, lefts panels). However, the treatment with the hormone for 60 and $90 \mathrm{~min}$ induces changes in c-Src protein expression in HCT116 cells (Fig. 2b, right panel). The fact that the doubling time of HCT116 cells is shorter than that observed in Caco-2 cells (21 $\mathrm{h}$ and $36 \mathrm{~h}$, respectively) and that the metabolic activity in HCT116 cells is higher than in Caco-2 cells may explain these findings showing that, after PTHrP treatment, Src is activated faster in HCT116 cells than in Caco-2 cells.

\subsection{PKC $\alpha$ levels decreased and increased in Caco-2 cells and HCT116 cells, respectively, after PTHrP treatment}

The stimulation of Ras/Raf/MEK/ERK cascade can also occur by direct activation of Raf via PKC (Plotnikov et al., 2011). Based on their structural and activation characteristics, PKC family can be classified into three subfamilies: conventional or classic PKC isozymes (cPKCs; $\alpha$, $\beta \mathrm{I}, \beta \mathrm{II}$, and $\gamma$ ), novel or non-classic PKC isozymes (nPKCs; $\delta, \varepsilon, \eta$, and $\theta$ ), and atypical PKC isozymes (aPKCs; $\zeta, \iota$, and $\lambda$ ). In cancer, many of these isozymes play a critical role in cell proliferation, survival, invasion, migration, apoptosis, angiogenesis, and anticancer drug resistance (Kang, 2014). With the aim to evaluate whether PKC family is also part of the PTHrP signaling mechanism in tumor intestinal cells, then we analyze the protein levels of PKC $\alpha$ in these cells treated with the hormone because it is known that the down-regulation of its expression increases cellular proliferation, decreases differentiation and enhances the transformed phenotype of Caco-2 cells (Scaglione-Sewell et al., 1998). Caco-2 cells and HCT116 cells were exposed to PTHrP for the times indicated in Fig. 3a followed by Western blot analysis of cell lysates with anti-PKC $\alpha$ antibody. As shown in Fig. 3a, PKC $\alpha$ protein levels decreased in Caco- 2 cells exposed with PTHrP for 60 min whereas the treatment with the hormone for $30 \mathrm{~min}$ increased protein expression of this isozyme in HCT116 cells. These results suggest that after PTHrP treatment, PKC $\alpha$ levels decreased and increased in Caco- 2 cells and HCT116 cells, respectively.

\subsection{PKC, Src and Akt signaling pathways modulate the phosphorylation and activation of ERK 1/2 induced by PTHrP in tumor intestinal cells}

It has been reported that Src causes colon cancer through multiple downstream signaling pathways, including PI3K/Akt (Chen et al., 2014). With respect to PKC, during cancer cell proliferation and survival several of their isozymes stimulate survival or proliferation through different signaling pathways such as PI3K/Akt (Kang, 2014). As we previously observed that PTHrP activates PI3K/Akt in tumor intestinal cells (Calvo et al., 2014; Martín et al., 2014), then we first evaluated if PKC and Src signaling pathways are involved in the phosphorylation/activation of Akt induced by PTHrP in these cells. To that end, Caco- 2 cells and HCT116 cells were pre-incubated with a specific inhibitor of PKC, Ro-318220 (200 nM) or with a specific inhibitor of Src, PP1 $(10 \mu \mathrm{M})$ and then treated for $60 \mathrm{~min}$ or $1 \mathrm{~min}$ with PTHrP, respectively. These times were selected because previously we observed that the phosphorylation/activation of Akt significantly increased at $60 \mathrm{~min}$ and at $1 \mathrm{~min}$ after PTHrP treatment in Caco-2 cells and HCT116 cells, respectively (Martín et al., 2014; Calvo et al., 2014). 

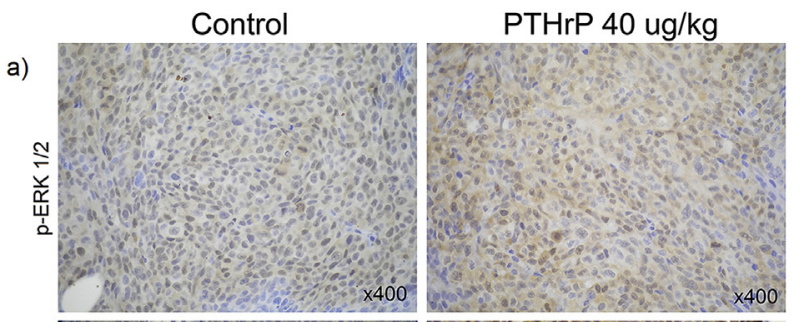

b)
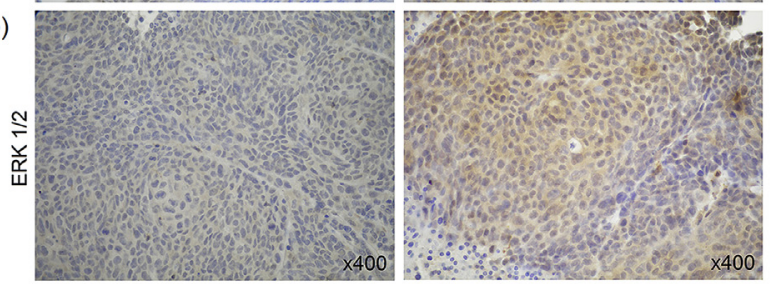

c)
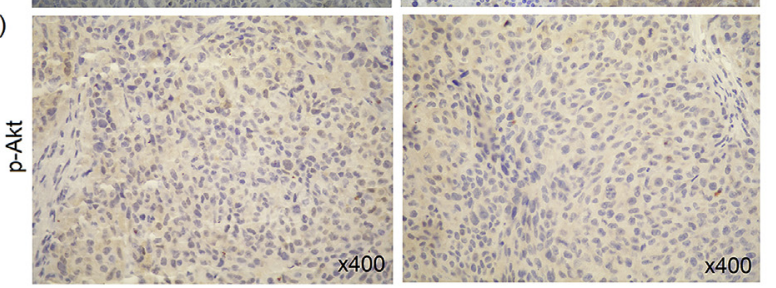

d)
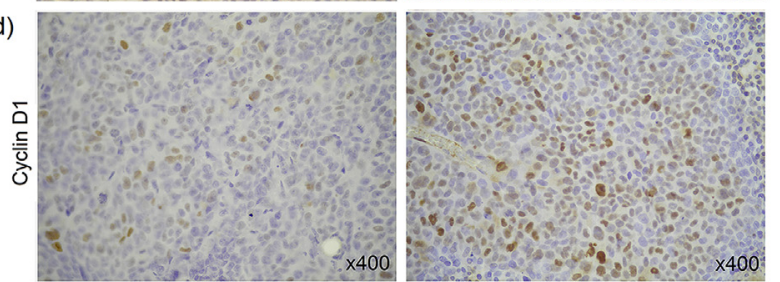

e)
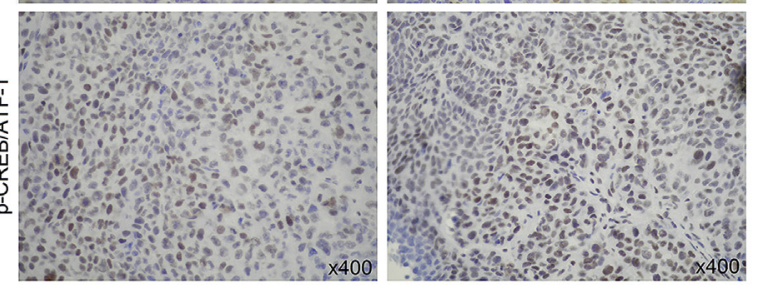

f)
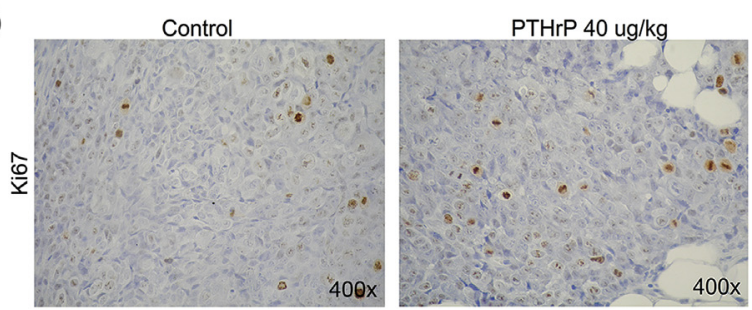

Total combined scores

a)

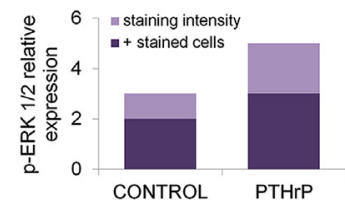

b)

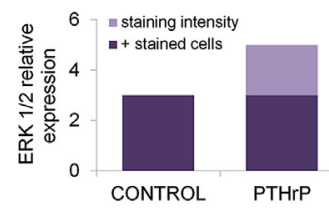

c)

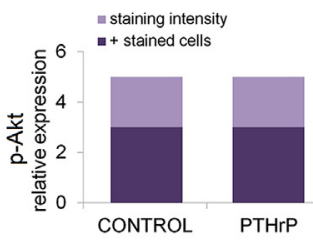

d)

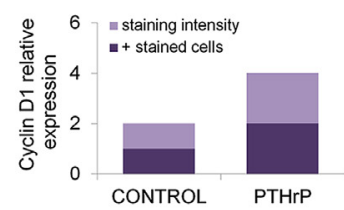

e)

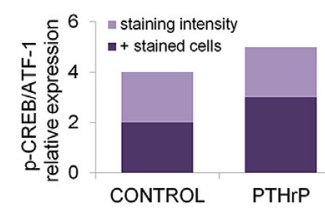

f)

Ki67 labelling index

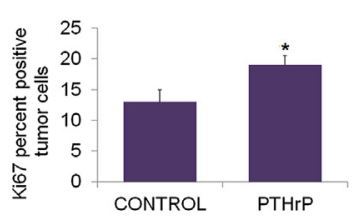

Fig. 1. Effects of PTHrP administration $(40 \mu \mathrm{g} / \mathrm{kg})$ in tumor xenografts.

Representative staining pattern of protein expression detected by immunohistochemistry (positivity + intensity) in HCT116 xenograft tumors. Tumor sections were stained with (a) anti-phospho ERK 1/2, (b) anti-ERK 1/2, (c) anti-phospho Akt (d) anti-Cyclin D1 (e) anti-phospho CREB/ATF1 and anti-Ki67 antibodies. Images are from tumor untreated (left) or treated with PTHrP (right). (a) Score of $2+1$ in control tumors and $3+2$ in treated tumors, (b) score of $3+0$ in control tumors and $3+2$ in treated tumors, (c) score of $3+2$ in control tumors and $3+2$ in treated tumors (d) score of $1+1$ in control tumors and $2+2$ in treated tumors, (e), score of $2+2$ in control tumors and $3+2$ in treated tumors, (f) The proliferation indices (based on Ki67 labelling, expressed in percentage) from untreated and treated tumor are shown. Magnification $\times 400$.
Western blot analysis using an anti-phospho-(Ser473) Akt antibody (which recognizes the active form of Akt) revealed that both inhibitors totally suppressed hormone-dependent Akt phosphorylation (Fig. 3b). Immunoblot analysis using an anti-Akt antibody revealed that the protein levels of total Akt were no different in the absence or presence of PTHrP at the times indicated, demonstrating a true increase in the phosphorylation status of Akt (Fig. 3b, left and right panels). DMSO, which is the vehicle of both inhibitors, was used in control cells.

In view of the participation of Src and PKC in the PTHrP signaling mechanism in tumor intestinal cells and taking into account that PI3K/ Akt pathway is necessary for the activation of ERK $1 / 2$ in many cell types (Ebi et al., 2013; Steelman et al., 2011) then our next objective was to investigate whether Src, PCK and Akt kinases are involved in the activation of ERK 1/2 MAPK triggered by PTHrP in both cell lines. To that end, these cells were pre-incubated with a specific inhibitor of Akt,
GSK690693 (50 nM), with a specific inhibitor of PKC, Ro-318220 $(200 \mathrm{nM})$, or with a specific inhibitor of Src, PP1 $(10 \mu \mathrm{M})$, and then treated for $60 \mathrm{~min}$ or $1 \mathrm{~min}$ with PTHrP, respectively. These times were selected because previously we observed that the phosphorylation/activation of ERK1/2 significantly increased at $60 \mathrm{~min}$ and at $1 \mathrm{~min}$ after PTHrP treatment in Caco- 2 cells and HCT116 cells, respectively (Calvo et al., 2017; Martín et al., 2014). Western blot analysis using specific anti-phospho-ERK 1/2 antibody (which recognizes the active form of ERK 1/2 MAPK) revealed that all inhibitors employed totally suppressed hormone-dependent MAPK phosphorylation in both, Caco2 cells and HCT116 cells (Fig. 4a). Immunoblot analysis using an antiERK $1 / 2$ antibody revealed that the protein levels of total ERK $1 / 2$ were no different in the absence or presence of PTHrP at the times indicated, demonstrating a true increase in the phosphorylation status of ERK $1 / 2$ (Fig. 4a, left and right panels). DMSO, which is the vehicle of these 

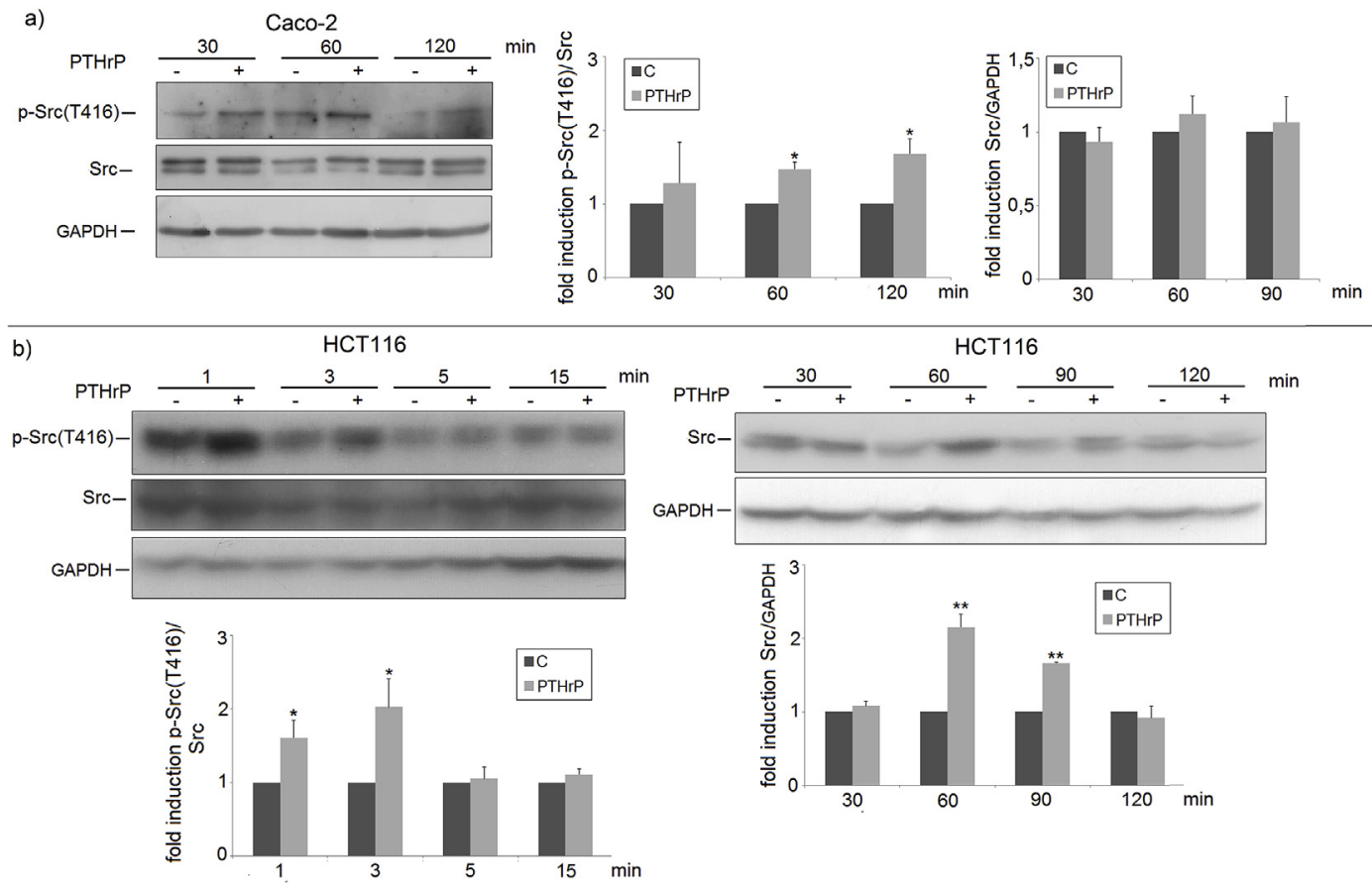

Fig. 2. PTHrP activates Src kinase pathway in tumor intestinal cell lines. (a) Caco-2 cells and (b) HCT116 cells were grown and incubated in the absence or presence of PTHrP (1-34) $10^{-8} \mathrm{M}$ for 30-120 min or 1-120 min, respectively. Western blot analysis of cell lysates was carried out using anti-phospho (Tyr416) Src and anti-Src antibodies. The membranes were stripped and reblotted with anti-GAPDH antibody to ensure the equivalence of protein loading. Representative immunoblots and the quantification by scanning densitometry of three independent experiments are shown; means \pm S.D. are given. *P $<0.05$, **P $<0.01$.

inhibitors, was used in control cells. Taken together, these results suggest that Src and PKC play a role upstream in the signaling mechanism leading to Akt and ERK $1 / 2$ activation by PTHrP in both cell lines. Also, once activated, Akt is able to activate ERK $1 / 2$.

Based on these results, the next approach was performed with an antibody against to type $1 \mathrm{PTH}$ receptor (PTH1R) to confirm that the cellular response is specific to PTHrP/PTH1R interaction. To that end, Caco- 2 cells and HCT116 cells were pre-incubated with the antibody $(5 \mu \mathrm{g} / \mathrm{mL})$ or with a non-specific IgG $(5 \mu \mathrm{g} / \mathrm{mL})$, as a control, followed by the treatment with PTHrP (1-34) for $1 \mathrm{~h}$ and $1 \mathrm{~min}$, respectively. As shown in Fig. 4b, Western blot analysis using specific anti-phospho-ERK $1 / 2$ antibody revealed that the antibody against PTHrP receptor totally suppressed hormone-dependent MAPK phosphorylation in both, Caco2 cells and HCT116 cells. The membranes were stripped and reblotted with anti-GAPDH antibody to ensure the equivalence of protein loading. These findings confirm that ERK activation in cell derived from CRC is exclusively by PTHrP/PTH1R interaction.

3.5. The expression changes of c-Myc and Cyclin D1 induced by PTHrP are dependent on ERK 1/2 signaling pathway in tumor intestinal cells

In CRC, it is well established the transcriptional activation of certain genes such as c-Myc and Cyclin D, which are two positive cell cycle regulators associated with tumor intestinal cells proliferation (El Khoury et al., 2016). In vitro we previously demonstrated that PTHrP increases the amount of these proteins in tumor intestinal cells (Martín et al., 2014) and herein we showed that the hormone also up-regulates Cyclin D protein expression in vivo; furthermore, this peptide positively modulates cell cycle progression and changes the expression of other proteins involved in cell cycle regulation via MAPK pathway (Calvo et al., 2014). In order to investigate whether the effect of PTHrP on the expression of c-Myc and Cyclin D1 is dependent upon ERK 1/2 pathway, tumor intestinal cells were pre-incubated in the presence or absence of PD98059 $(20 \mu \mathrm{M}$ ), a specific inhibitor of MEK1/2 (which are upstream kinases of ERK1/2), and then treated with the hormone for 1 or $2 \mathrm{~h}$ followed by immunoblot analysis using specific antibodies. As shown in Fig. 4c, when Caco-2 cells were incubated with the inhibitor, the PTHrP response is reverted. Taken together, these results indicate that the effect of PTHrP on the protein expression of c-Myc and Cyclin D1 is dependent of ERK 1/2 MAPK pathway.

\subsection{PTHrP attenuates the effect of CPT-11 in tumor intestinal cells}

The results shown by us in previous studies and in the present work demonstrated the key role of PTHrP in the modulation of molecular mechanisms related to tumorigenic events both in vitro and in vivo. Since PTHrP can mediate chemoresistance effects in other models (Cui et al., 2016; Gagiannis et al., 2009), then we investigated whether the peptide can also modify tumor intestinal cell response to the chemotherapeutic agent CPT-11. To that end Caco- 2 cells and HCT116 cells were treated with CPT-11 $(10 \mu \mathrm{M})$ alone or in combination with PTHrP. As shown in Fig. 5 (left panel), counting live cells by means of Trypan blue dye exclusion revealed that the treatment with the drug significantly decrease the number of viable Caco- 2 cells respect to the number of viable Caco-2 cells untreated (dark purple bars). Fig. 5 (right panel, dark purple bars) shows a significant decrease of the number of viable HCT116 cells treated with the drug respect to the number of viable HCT116 cells untreated. However, the treatment with PTHrP for 5 days in Caco- 2 cells or $24 \mathrm{~h}$ in HCT116 cells attenuated the cytotoxicity induced by CPT-11 (light purple bars, Fig. 5 left and right panels). We selected these times of PTHrP treatment because in previous studies we observed that the maximum response in cell proliferation is achieved at 5 days and 1 day of PTHrP exposure in Caco- 2 cells and HCT116 cells, respectively.

\subsection{The effects of CPT-11 on the levels of pro-apoptotic and anti-}

proliferative factors necessary for the cytotoxic response in intestinal tumor cells are counteracted by PTHrP

The increase in the expression of certain negative cell cycle regulators such as p21, p27 and p53 as well as the decrease in the expression of molecules with anti-apoptotic activity such as Bcl-2 can 

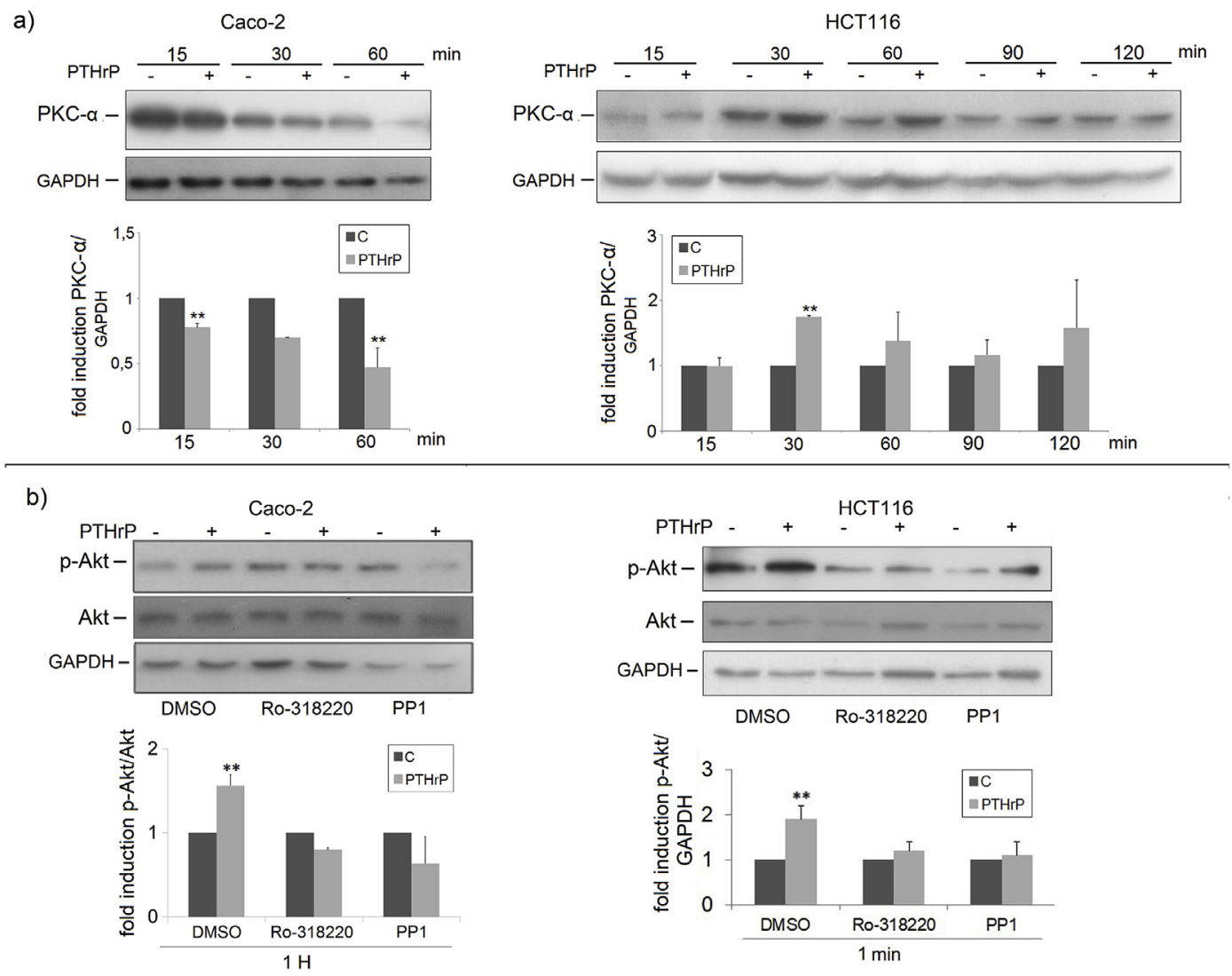

Fig. 3. (a) Effects of PTHrP on PCK $\alpha$ expression. Caco-2 cells and HCT116 cells were treated with or without PTHrP (1-34) $10^{-8} \mathrm{M}$ for $15-60$ min and $15-120$ min, respectively. Proteins from lysates were prepared as described in Methods, separated on SDS-PAGE, and immunoblotting using anti- PCKa antibody. In order to evaluate the equivalence of protein content among the different experimental conditions, blotted membranes were reproved with anti-GAPDH antibody. Representative immunoblots and the quantification by scanning densitometry of three independent experiments are shown; means \pm SD are given. **P $<0.01$, with respect to the corresponding control. (b) Involvement of PKC and Src signaling pathways in the phosphorylation and activation of Akt induced by PTHrP. Caco-2 cells and HCT116 cells were pre-incubated for $30 \mathrm{~min}$ with Ro-318220 (200 nM) or PP1 (10 $\mu \mathrm{M})$ and then exposed to PTHrP (1-34) $10^{-8} \mathrm{M}$ for $60 \mathrm{~min}$ or $1 \mathrm{~min}$, respectively, followed by Western blot analysis of proteins from cell lysates using anti-phospho (Ser473) Akt antibody. Blotted membranes were reproved with anti-Akt and anti-GAPDH antibodies in order to demonstrate a true increase in the phosphorylation status of Akt and to ensure the equivalence of protein loading, respectively. Representative immunoblots and the quantification by scanning densitometry of three independent experiments are shown; means \pm SD are given. ${ }^{*} \mathrm{P}<0.01$, with respect to the corresponding control.

predict a favorable evolution in patients with CRC treated with CPT -11 (Charara et al., 2004). In addition, the activation of the apoptotic effector caspase- 3 and consequently the cleavage of its substrate, polyADP ribose polymerase (PARP), are expected events once the CRC tumor cells respond to CPT-11 (Yang et al., 2016b). Taking into account that PTHrP exerts a protective effect under apoptotic conditions (Lezcano et al., 2013) and also negatively modulates several cell cycle inhibitors (Calvo et al., 2014), we decided to evaluate the expression of relevant molecular markers associated with these cellular responses in both Caco- 2 cells and HCT116 cells treated with CPT-11 alone or in combination with PTHrP. For this purpose, the cells were initially exposed to the drug or the drug plus the hormone for 8,24 and $48 \mathrm{~h}$; these times were selected according to previous studies carried out in our laboratory (Calvo et al., 2014; Lezcano et al., 2013). Western blot analysis of the protein from lysates of HCT116 cells using anti p27, anti Bcl-2 and anti-cleaved PARP antibodies, revealed that both, the increase in protein levels of p27 inhibitor and the cleaved form of PARP, as well as the decrease in protein levels of Bcl-2 induced by the treatment with CPT-11 were reversed by exposure of the cells to PTHrP plus CPT-11 (Fig. 6 top panel), suggesting that PTHrP decreases the sensitivity to CPT-11 in HCT116 cells through the modulation of the protein expression of at least Bcl-2 and p27 and through the modulation of the activity of caspase- 3 . However, we did not observed changes in the expression levels of these proteins in the Caco-2 cell line due to treatment with CPT-11 or with PTHrP plus CPT-11 (Fig. 6 bottom panel), suggesting that the drug affects the viability of this cell line through other mechanisms than those observed in the tumor intestinal line HCT116.

\subsection{The ERK signaling pathway participates in the chemoresistance to CPT-} 11 induced by PTHrP

Previous works revealed that p38 MAPK pathway is involved in the sensitivity to CPT-11 and suggest that the level of phosphorylated p38 could be used as a marker of clinical resistance to CPT-11, and that the signaling pathway of p38 MAPK could be a therapeutic target to overcome the resistance to CPT-11-based chemotherapies in the CRC (Paillas et al., 2011). In addition, it has been observed that the activation of ERK in the HCT116 cell line can generate resistance to other antitumor agents such as Erlotinib, which inhibits the kinase activity of the epidermal growth factor receptor (Chen et al., 2007). Since PTHrP activates ERK MAPK both in vitro and in vivo and several signaling pathways activated by the hormone converge in the activation of ERK MAPK, then we evaluated whether the use of a specific inhibitor of this signaling pathway (PD98059 $20 \mathrm{mM}$ ) restores the sensitivity of intestinal tumor cells to CPT-11, even in the presence of PTHrP. Counting live cells by means of Trypan blue dye exclusion revealed that the blockade of ERK restored the inhibition of cell growth due to the treatment with the chemotherapeutic in Caco-2 cells and in HCT116 cells (Fig. 7a light purple bars marked with the symbol \#\#). 

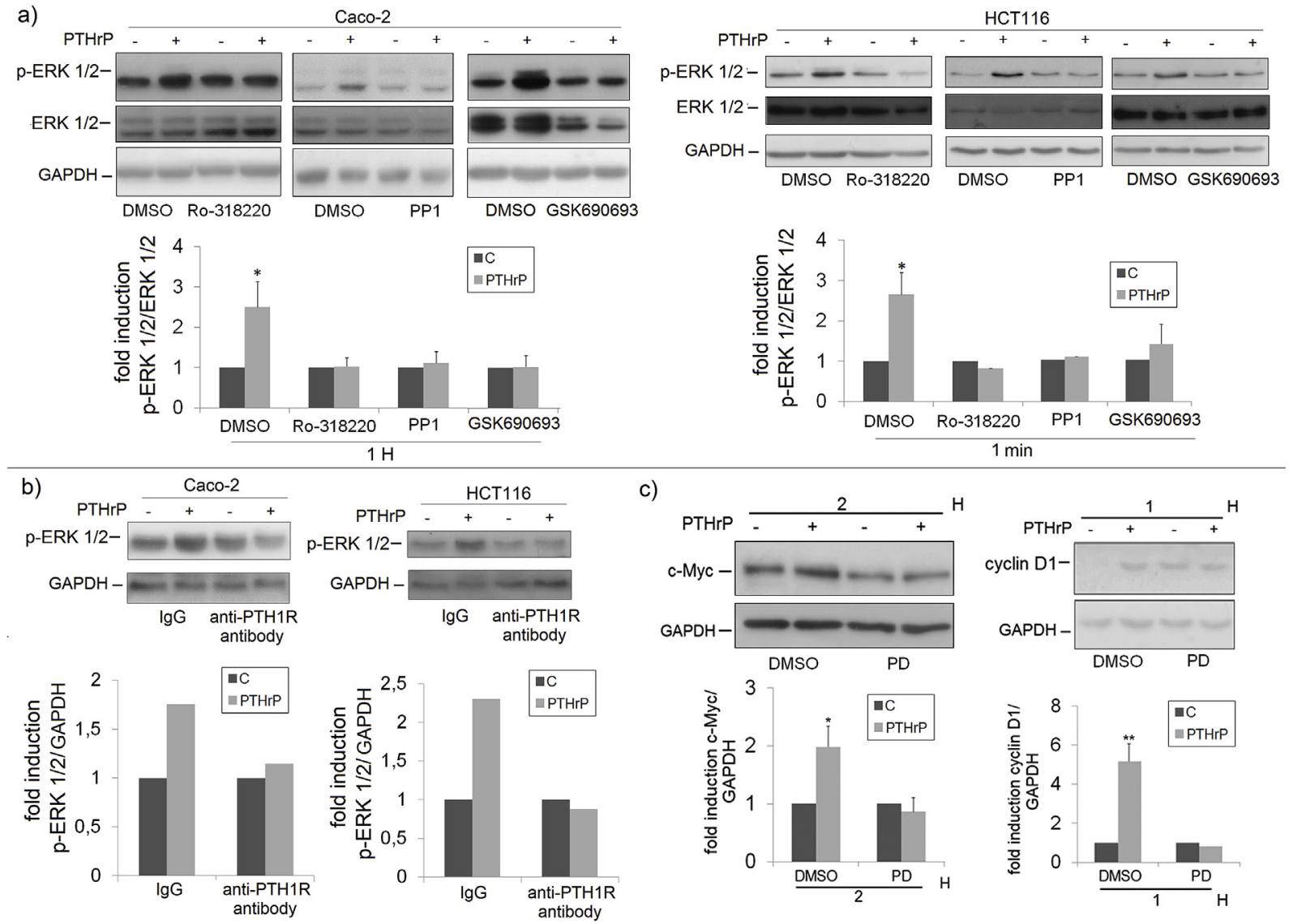

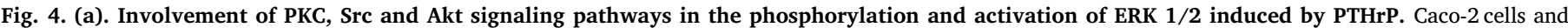

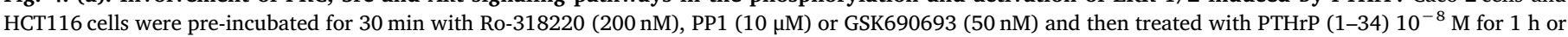

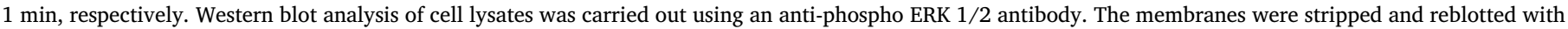

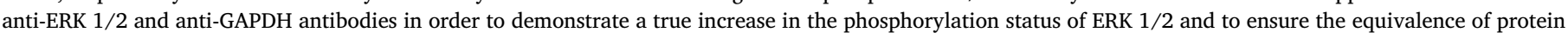

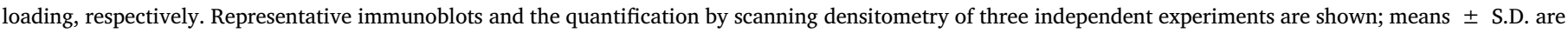

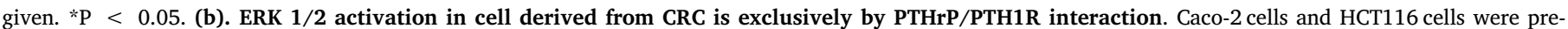

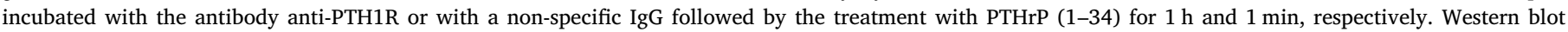

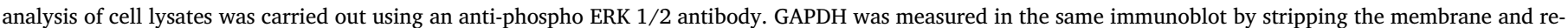

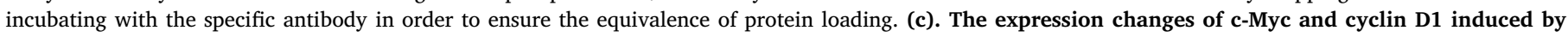

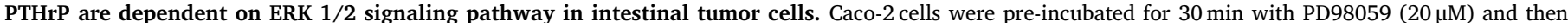

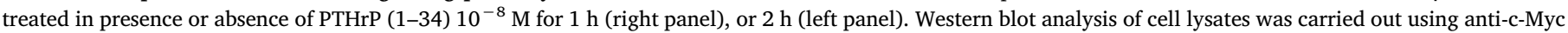

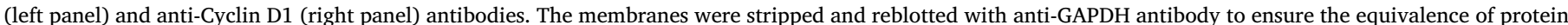

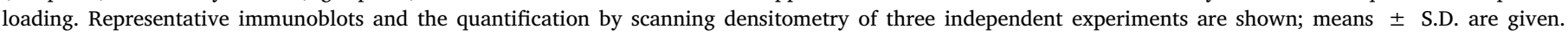
$* \mathrm{P}<0.05, * * \mathrm{P}<0.01$.
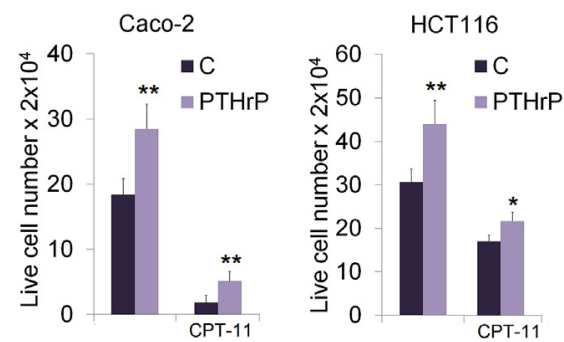

Fig. 5. PTHrP decreases the response of intestinal tumor cells to CPT-11. Caco-2 (a) and HCT116 (b) cells were treated with PTHrP and/or CPT-11 $(10 \mu \mathrm{M})$ for 5 days (a) or 1 day (b). The number of viable cells was counted by Trypan blue staining using a Newbauer chamber. The average of the results obtained from three independent experiments is shown. ${ }^{*} \mathrm{P}<0.05$, $* * \mathrm{P}<0.01$. (For interpretation of the references to color in this figure legend, the reader is referred to the Web version of this article.)
We observed that the inhibition of Akt pathway by the use of the Akt inhibitor GSK690693 (50 nM) also restore CPT-11 action in Caco-2 cells and in HCT116 cells (Fig. 7b, light purple bars marked with the symbol \#, left panel, and the symbol \#\#, right panel). Taken together, these results suggest that PTHrP attenuates the cytotoxicity of CPT-11 through the ERK pathway and through the Akt pathway which lead to ERK 1/2 MAPK activation in both Caco-2 cells and HCT116 cells.

\section{Discussion}

Herein we provide several evidences of the role of exogenous PTHrP as a regulator of tumor proliferation markers expression in vivo. It have been reported the effects of PTHrP overexpressed in tumor xenografts of Lovo cells (Shen et al., 2007); however, and since that the vast majority of PTHrP actions are paracrine in nature (Maioli and Fortino, 2004), we decided to evaluate the action of the hormone produced from an external source and therefore we injected PTHrP into the tumors. We previously reported the activation in vitro of mitogenic signaling pathways in Caco-2 cells and HCT116 cells after PTHrP exposure (Calvo et al., 2014, 2017; Martín et al., 2014). In this work, we showed, for the 
a)

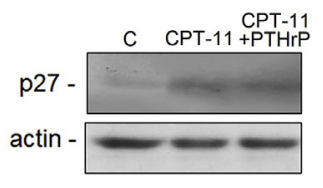

$8 \mathrm{H}$

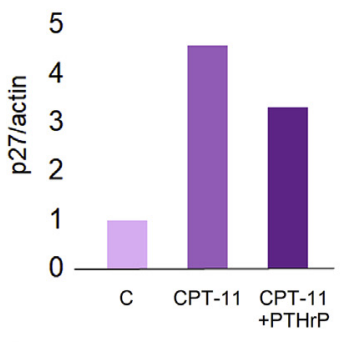

\section{HCT116}

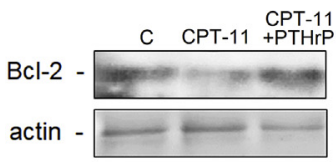

$8 \mathrm{H}$

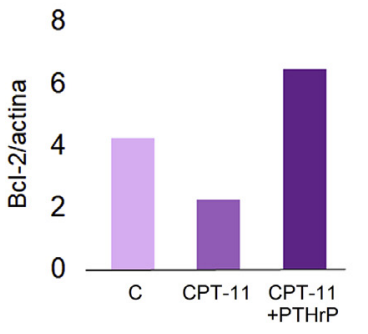

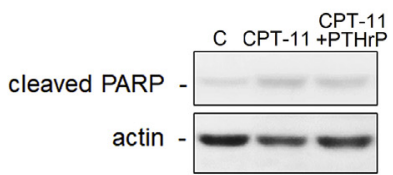

$24 \mathrm{H}$

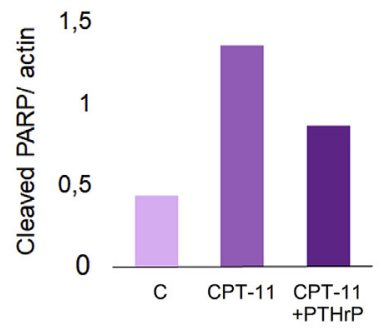

Fig. 6. PTHrP reverses the changes in the expression levels of p27, Bcl-2 and cleaved PARP due to treatment with CPT-11 in the HCT16 cell line but not in the Caco-2 cells. HCT116 (a) and Caco-2 (b) cells were cultured and incubated in the absence or presence of PTHrP (1-34) $10^{-8} \mathrm{M}$ for 8-48 h. Analysis by Western blot technique of cell lysates was carried out using anti-p27, anti-Bcl-2 and anti-PARP antibodies. The membranes were re-incubated with anti-actin antibody to ensure equivalence of protein loading.

b)

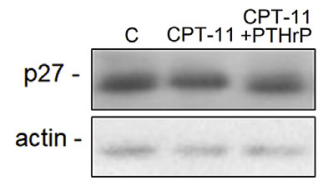

$8 \mathrm{H}$

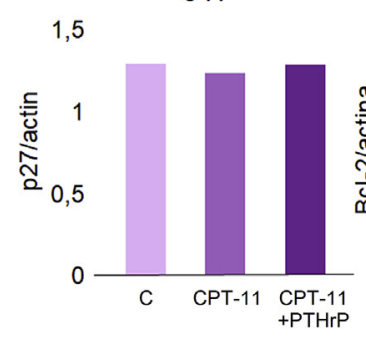

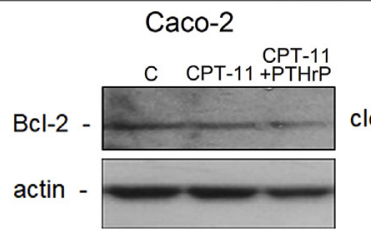

$8 \mathrm{H}$

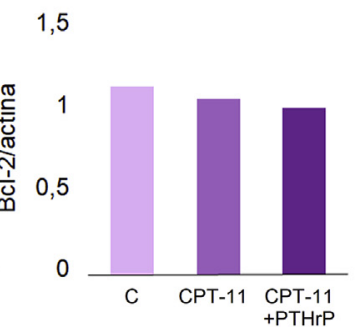

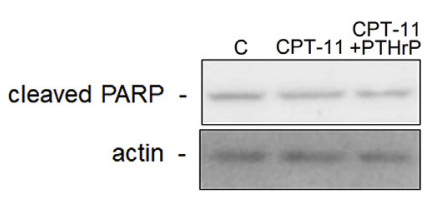

$24 \mathrm{H}$

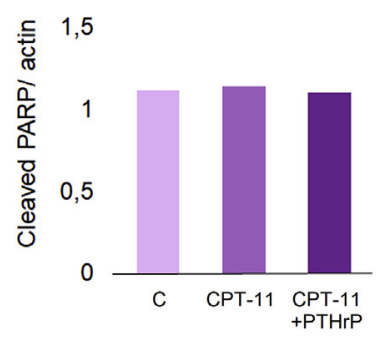

first time, that intratumoral PTHrP administration in nude mice xenografts increases the levels of several positive regulators of cell proliferation, including ERK MAPK. The fact that we did not observe the same effect on the activation of Akt signaling suggests that PTHrP in vivo may exert its effects through ERK MAPK but independently of Akt. Other investigators have observed that PTHrP administrated in animals exerts anabolic effects in cancellous and cortical bone and/or improves bone strength in osteopenic rodents and humans (Stewart et al., 2000), while the present investigation provides, to our knowledge, additional evidence demonstrating that exogenous PTHrP regulates signaling pathways associated with proliferation in animal models. Taken together, these findings emphasize the endocrine/paracrine action of the hormone in in vivo models.

The results showed in this work indicate that PTHrP induces the phosphorylation and activation of Src kinase in Caco- 2 cells and HCT116 cells. The phenotypic differences between both cell types due to variants in genes mutations (Ahmed et al., 2013) may explain the fact that the hormone up-regulates the protein levels of Src, at least at the times studied, in HCT116 cells but not in Caco- 2 cells. Recently, we observed that PTHrP activates the tumorigenic $\beta$-catenin pathway independently of Wnt signaling and in both type of cells derived from CRC studied by us, Caco- 2 cells (with APC mutant) and HCT116 cells
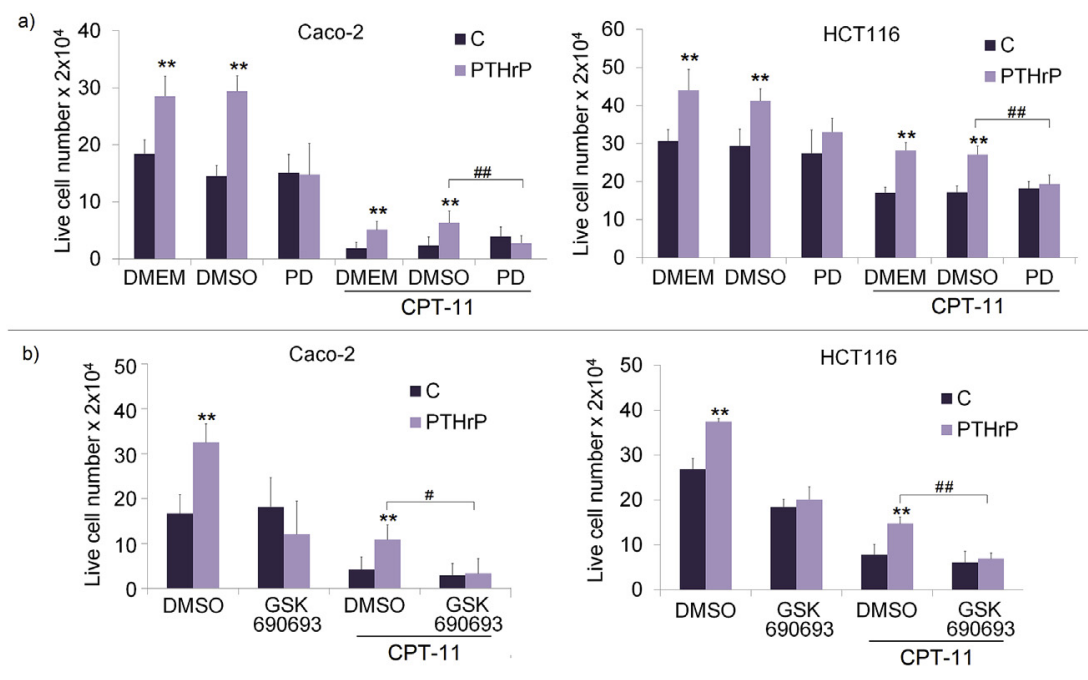

Fig. 7. (a) PTHrP attenuates the cytotoxicity of CPT-11 through the ERKMAPK pathway and (b) through the Akt pathway which lead to ERK 1/2 MAPK activation. Caco-2 (right panels) and HCT116 cells (left panels) were pre-incubated with the inhibitors PD98059 $(20 \mathrm{mM})$ (a) or GSK690693 $(50 \mathrm{nM})($ b) for $30 \mathrm{~min}$ and then treated with PTHrP and/or CPT-11 for 5 days (right panels) or 1 day (left panels). The number of viable cells was counted by Trypan blue staining using a Newbauer chamber. DMSO was used as a vehicle of both inhibitors. The average of the results obtained from 2 independent experiments is shown. $* * \mathrm{P}<0.01, \# \mathrm{P}<0.05, \# \# \mathrm{P}<0.01$. (For interpretation of the references to color in this figure legend, the reader is referred to the Web version of this article.) 
(with APC wild type). We also found that some mitogenic signaling pathways mediate this activation by phosphorylation (Martin et al., 2014; Martin M.J., personal data). Under this scenario, in HCT116 cells perhaps the increase of the transcriptional activity mediated by $\beta$-catenin may lead to the induction of Src gene expression. In addition, the presence of hyperactivating KRAS mutation in HCT116 cells (Ahmed et al., 2013) may explain the increased Src protein expression because in these cells treated with PTHrP, RAS may modulate Src expression via RAS-ERK pathway and/or via RAS-ERK- $\beta$-catenin pathway. So, although APC mutation is not present in HCT116 cell line (Ilyas et al., 1997), it is possible that other mechanisms acting in concert to facilitate $\beta$-catenin nuclear translocation and the subsequent increase of the transcriptional activity mediated by $\beta$-catenin leading to the modulation of Src expression. More experiments are needed to corroborate this idea.

Src activity is increased in $80 \%$ of CRC patients, which indicates its importance in the disease (Lieu and Kopetz, 2010). An activating mutation of the Src gene is found in $12 \%$ of patients. This mutation accounts for only a small proportion of Src activation in colon cancer. Furthermore, several other studies have not detected mutations in this kinase in colon cancer (Chen et al., 2014). These data suggest that activated Src is more likely a mediator of cellular signals that are induced upstream of Src. The role of Src in colon cancer progression is confirmed by its increased activity with the progression from benign polyps to carcinoma to metastatic cancer. Src is higher in human early-stage malignant polyps but not in benign polyps, which suggests that Src is significantly related to the progression of colon cancer (Irby and Yeatman, 2000). Other studies have also shown that Src activity is much higher in metastatic colon cancer than in non-metastatic colon cancer (Chen et al., 2014).

Our results suggest that after PTHrP treatment, PKC $\alpha$ levels decreased and increased in Caco- 2 cells and HCT116 cells, respectively. It is known that PKC isozymes can exhibit similar expression patterns and roles in multiple types of cancer. However, in some cases, they can show specific expression and function that is dependent on the type of cancer (Kang, 2014). Several studies showed discordant results respect to the role of $\mathrm{PKC} \alpha$ in colon cancer progression: although increasing evidence shows that PKC $\alpha$ does participate in growth arrest and cancer suppression in the intestine epithelium (Garg et al., 2014), a recent study has suggested that $\mathrm{PKC} \alpha$ activation is involved in the activation of ERK1/2/NF- $\kappa$ B through the tissue factor/VIIa/PAR2 pathway and this signaling pathway leads to enhanced proliferation, migration, and survival for the colon cancer cell line SW620 (Wu et al., 2013). Alternately, PKC $\alpha$ can also enhance cell adhesion and anticancer resistance through a different signal pathway than that used during anti-proliferation. High migratory activity of colon cancer cells is related to high PKC $\alpha$ and low E-cadherin expression (Masur et al., 2001), in this context, the down-regulation of PKC $\alpha$ may increase the sensitivity to anticancer agents (Kang, 2014).

Herein we demonstrated that Src signaling pathway modulates the phosphorylation of Akt and ERK 1/2 induced by PTHrP in tumor intestinal cells. It is known that Src regulates PI3K by directly phosphorylating the $\mathrm{p} 85$ subunit of PI3K and inhibiting the PI3K negative regulator phosphatase (PTEN). Src recruits PI3K to an activated membrane compartment and phosphorylates $\mathrm{p} 85$ at Tyr688. The phosphorylation of this p85 subunit leads to the reduced inhibition of another PI3K subunit, the catalytic p110. These series of events lead to an increase in PI3K activity. Src also reduces the action of PTEN, which inhibits PI3K. The activation of PI3K increases the phosphorylation of Akt via phosphoinositide-dependent kinase (PDK). In addition, Src regulates Ras-Raf-MEK-ERK1/2 pathway activating c-Ras, which is the main regulator of MAPK. Ras activates Raf, which in turn activates MEK, and MEK activates ERK 1/2 (Frame, 2004).

In this work, studies with Ro 31-820, which is a specific inhibitor of the activity of several PKC isoforms, showed that PTHrP regulates the activation of Akt and ERK 1/2 through of at least one isozyme of PKC.
$\mathrm{PKC} \alpha$ is an isozyme that also has been broadly studied in relation to cancer (Marengo et al., 2011). PKC $\alpha$ is positively modulated in its expression and/or in its activation (by phosphorylation) to promote the aggressive behavior of tumor intestinal cells (Kang, 2014). We suppose that PKC $\alpha$ may be involved in this response to PTHrP in Caco- 2 cells as well as in HCT116 cells since in both tumor intestinal cell lines, the treatment with the phorbol ester TPA under conditions that activate PKC (100 nM, $15 \mathrm{~min}$ ) significantly increased the phosphorylation of $\mathrm{PKC} \alpha$ whereas this effect was reversed in TPA-treated cells and in the presence of Ro 31-820 at a dose of $200 \mathrm{nM}$ (Martín M.J., unpublished). Other colleagues demonstrate that bradykinin acts as a proliferative agent in breast cancer cells activating intracellular pathways such as $\mathrm{PKC} \alpha$, Akt and ERK1/2 and that PKC $\alpha$ is involved in the activation of ERK 1/2 (Greco et al., 2006).

It has been reported that PKC $\alpha$ is phosphorylated and activated by Src favoring the aggressive phenotype of intestinal tumor cells and the consequent progression of CRC (McKinley et al., 2013). Studies employing the normal cell line PC12, derived from rat pheochromocytoma, showed that PKC-1 and PKC- $\zeta$, which are two atypical PKC, are also phosphorylated and activated by Src (Wooten et al., 2001). Additionally, PI3K has been shown to regulate the activity of PKC in cancer, in an AKT-independent manner through poorly characterized mechanisms that leads to survival, cytoskeletal rearrangement and transformation (Vivanco and Sawyers, 2002). Luna-Ulloa and colleagues demonstrated that PKC $\zeta$ interacts with $\beta$-catenin in cells derived from CRC. These investigators found that PKC $\zeta$ activity regulates the nuclear localization of $\beta$-catenin in a mechanism that does not involve $\beta$-catenin degradation (Luna-Ulloa et al., 2011). Perhaps in our experimental model at least one isozyme of PKC activated by PTHrP acts in concert with others signaling pathway to facilitate $\beta$-catenin nuclear translocation and the subsequent increase in the transcriptional activity mediated by $\beta$-catenin leading to the induction of PKC $\alpha$ expression in HCT116 cells. More studies are necessary to elucidate which PKC iso$\mathrm{zyme} / \mathrm{s}$ is/are involved in the activation of ERK and Akt and which are the mechanisms involved in the regulation of the expression and/or activation of PKC.

We previously showed that PTHrP induced the expression of Cyclin D1 and c-Myc in tumor intestinal cells (Martín et al., 2014) and herein we demonstrated that the hormone upregulates the expression of both positive regulators of cell proliferation through ERK 1/2 MAPK. The proto-oncogene MYC is one of several well-known transcription factors involved in the genesis and progression of many types of cancer acting as a main regulator of the expression of genes involved in cell proliferation and invasion. In CRC, c-Myc protein expression is known to be up-regulated in up to 70\% of cases (Boudjadi and Beaulieu, 2016); moreover, it has been found that RTK/RAS/MEK/ERK pathway enhance c-Myc protein stabilization by phosphorylation (Boudjadi et al., 2016) and that the phosphorylation by ERK1/2 of LRP6 (which is a key component of the Wnt pathway) with the consequent up-regulation of c-Myc may provide a unique point of convergence between MAPK and Wnt/ $\beta$-catenin signalings during oncogenesis (Lemieux et al., 2015). Perhaps in both tumor intestinal cell lines studied in this work, the increase in this onco-protein expression by PTHrP may be due to c-Myc protein stabilization by phosphorylation together with its up-regulation. More experiments are necessary to confirm this hypothesis. With respect of Cyclin D1, this and other cell cycle-regulatory proteins are essential for cell cycle progression from G1 to $S$ phase; there is evidence that its expression can be down-regulated by PKC $\alpha$ but markedly is upregulated by $\mathrm{PKC} \varepsilon$ through ERK pathway. Again, these findings highlight opposing actions of PKC family members and the role of ERK, which converge in the modulation of Cyclin D1 expression, as important regulators of tissue homeostasis and tumorigenesis in the intestine (Pysz et al., 2014).

Herein we evidenced, for the first time, that PTHrP induces resistance to CPT-11, which is a topoisomerase inhibitor, in Caco-2 and HCT116 cells. PTHrP induces resistance to others topoisomerase 


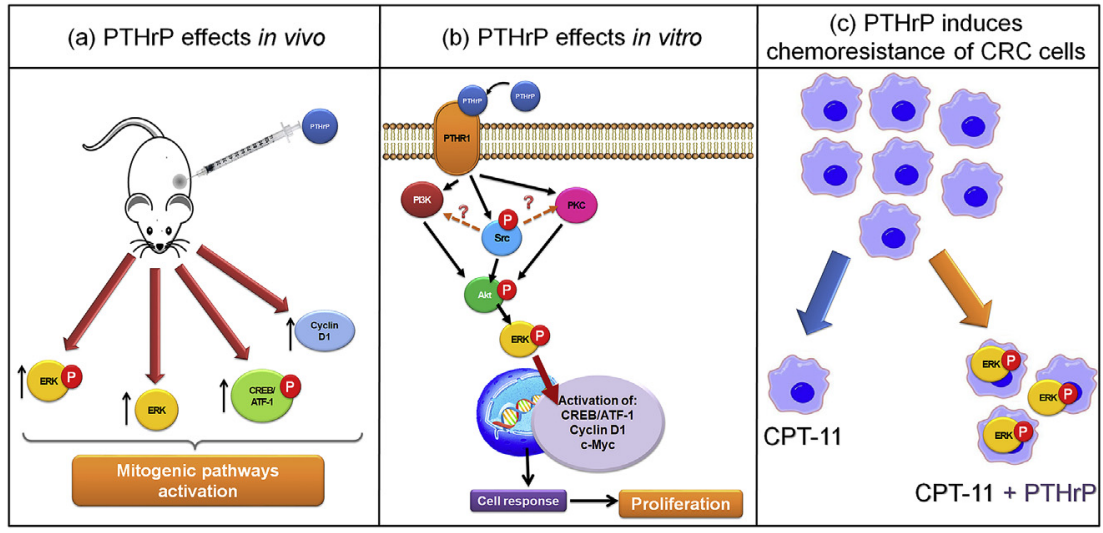

Fig. 8. Molecular effects induced by PTHrP in in vivo and in vitro CRC models. (a) Daily intratumoral PTHrP administration in nude mice xenografts increases the expression and/or induces the activation of several positive cell cycle and proliferation regulators. (b) Signal transduction pathways leading to the activation of ERK $1 / 2$ and its targets by exogenous PTHrP in human CRC cells (c) Chemoresistance induced by PTHrP through ERK $1 / 2$ in CRC cells (this figure is original for this manuscript). inhibitors such us doxorubicin and mitoxantrone in tumor cell lines derived from osteosarcoma (Gagiannis et al., 2009). However, it is known that PTHrP can also mediate chemoresistance to docetaxel in tumor cell lines derived from prostate (Cui et al., 2016). The antitumor activity of this drug is based on stabilization of the microtubule dynamics and thereby disruption of the cell cycle (de Weger et al., 2014). Taken together, these data indicate that PTHrP-induced resistance is not only specific to topoisomerase inhibitors.

This work shows that ERK signaling pathway participates in the chemoresistance to CPT-11 induced by PTHrP in cells derived from CRC. Chemotherapeutic drug resistance is a frequent cause of treatment failure in CRC patients. Understanding the cellular mechanisms that lead to this resistance should allow an improvement in the treatment of CRC. CPT-11 resistance in CRC appears to develop by a few mechanisms including low intratumor level of the active metabolite SN-38, a decrease in expression of topoisomerase I, change in the activity of the SN38-Topo I- DNA complex, and changes in downstream events such as suppression of apoptosis, cell cycle alterations, or enhancement of DNA repair (Hammond et al., 2016). Recently, the use of compounds that target components of the ERK signaling pathway, such as Raf or MEK inhibitors, has led to a substantial improvement in the clinical outcome in another type of cancer, metastatic melanoma, and has shown promising clinical activity in other types of tumors. However, the response and efficacy of these drugs are highly variable and is mainly limited by the development of resistance. Both intrinsic and acquired resistance to Raf and MEK inhibitors are frequently associated with the persistence of ERK signaling, which implies the need for more innovative approaches to address the pathway (Samatar and Poulikakos, 2014).

\section{Conclusion}

In conclusion, this work expands our knowledge about the molecular mechanisms modulated by exogenous PTHrP in vivo and in vitro. We demonstrated that continue administration of this hormone in nude mice xenografts activates ERK 1/2 MAPK and other components of mitogenic signaling pathways. Also, our results indicate that Src, PKC and Akt play a role upstream in the signaling mechanism leading to ERK 1/2 MAPK activation by PTHrP in two CRC cell lines which are phenotypically different. Furthermore, herein we demonstrate, for first time, that PTHrP induces resistance to a chemotherapeutic drug in CRC cells and that this effect is mediated through ERK signaling (Fig. 8).

The investigations of the last decade indicate that PTHrP is a bioactive factor in the initiation, growth and invasion of several carcinomas. In 2007, Nishihara and colleagues revealed that $95 \%$ of patients with CRC overexpress PTHrP being the level of expression higher in the less differentiated adenocarcinomas than those with the highest degree of differentiation (Nishihara et al., 2007). Despite these interesting data, a recent publication that carries out an exhaustive review of articles reveals only 29 reported cases of CRC associated with PTHrP and hypercalcemia (Galindo et al., 2016), we think that this situation may imply a lack of knowledge of the existence of many more cases of CRC in which PTHrP is one of the factors that contribute to the genesis and progression and even chemoresistance responses of this disease.

The results shown in the present work emphasize the key role of ERK as a mediator of tumorigenic events and chemoresistance induced by PTHrP in cells derived from CRC. The understanding of the molecular mechanisms involved in the activation of ERK $1 / 2$ and the study of ERK signaling targets may facilitate the development of new therapeutic strategies for CRC treatment.

\section{Funding and acknowledgements}

This study was funded by Agencia Nacional de Promoción Científica y Tecnológica (ANPCYT) (PICT-2013-1441), Consejo Nacional de Investigaciones Científicas y Técnicas (CONICET) (PIP112-20110100409), Instituto Nacional del Cáncer (Resolución Ministerial 493/14; RESOL-2016-1006-E-APN-MS) and Universidad Nacional del Sur (PGI: 24/B188; PGI: 24/B230), Argentina. The funding sources had no involvement in study design; in the collection, analysis and interpretation of data; in the writing of the report; and in the decision to submit the article for publication.

Special acknowledgment to Dr. Martín Abba and collaborators, CINIBA - Fac. de Cs. Médicas, Universidad Nacional de La Plata, Argentina, and to Dr. Horacio Maturi from Depto. De Biología, Bioquímica y Farmacia, Universidad Nacional del Sur, Argentina.

All applicable international, national, and/or institutional guidelines for the care and use of animals were followed. All experiments with animals were approved by a local animal committee for ethics (CICUAE-UNS) and were carried out in accordance with the National Institutes of Health guide for the care and use of Laboratory animals (NIH, 1996).

This article does not contain any studies with human participants performed by any of the authors.

\section{Declaration of interests}

None.

\section{References}

Ahmed, D., Eide, P.W., Eilertsen, I.A., Danielsen, S.A., Eknæs, M., Hektoen, M., Lind, G.E., Lothe, R.A., 2013. Epigenetic and genetic features of 24 colon cancer cell lines. Oncogenesis 2, e71. https://doi.org/10.1038/oncsis.2013.35.

Allen, D.C., 2006. Histopathology Reporting: Guidelines for Surgical Cancer. second ed. Springer, London.

Arnold, M., Sierra, M.S., Laversanne, M., Soerjomataram, I., Jemal, A., Bray, F., 2017 Global patterns and trends in colorectal cancer incidence and mortality. Gut 66, 683-691. https://doi.org/10.1136/gutjnl-2015-310912.

Botchkina, I.L., Rowehl, R.A., Rivadeneira, D.E., Karpeh Jr., M.S., Crawford, H., Dufour, A., Ju, J., Wang, Y., Leyfman, Y., Botchkina, G.I., 2009. Phenotypic subpopulations of metastatic colon cancer stem cells: genomic analysis. Canc.Genom. Proteom. 6, 
$19-29$.

Boudjadi, S., Beaulieu, J., 2016. MYC and integrins interplay in colorectal cancer. Oncoscience 3, 50-51. https://doi.org/10.1038/onc.2015.231.6.7.Groulx.

Boudjadi, S., Carrier, J.C., Groulx, J.-F., Beaulieu, J.-F., 2016. Integrin $\alpha 1 \beta 1$ expression is controlled by c-MYC in colorectal cancer cells. Oncogene 35, 1671-1678. https://doi. org/10.1038/onc.2015.231.

Calvo, N., Carriere, P., Martin, M.J., Gentili, C., 2017. RSK activation via ERK modulates human colon cancer cells response to PTHrP. J. Mol. Endocrinol. 59, 13-27. https:// doi.org/10.1530/JME-16-0216.

Calvo, N., Gentili, C., de Boland, A.R., 2011. Parathyroid hormone and the regulation of cell cycle in colon adenocarcinoma cells. Biochim. Biophys. Acta Mol. Cell Res. 1813, 1749-1757. https://doi.org/10.1016/j.bbamcr.2011.06.001.

Calvo, N., Martin, M.J., de Boland, A.R., Gentili, C., 2014. Involvement of ERK1/2, p38 MAPK, and PI3K/Akt signaling pathways in the regulation of cell cycle progression by PTHrP in colon adenocarcinoma cells. Biochem. Cell. Biol. 92, 305-315. https:// doi.org/10.1139/bcb-2013-0106.

Charara, M., Edmonston, T.B., Burkholder, S., Walters, R., Anne, P., Mitchell, E., Fry, R. Boman, B., Rose, D., Fishel, R., Curran, W., Palazzo, J., 2004. Microsatellite status and cell cycle associated markers in rectal cancer patients undergoing a combined regimen of 5-FU and CPT-11 chemotherapy and radiotherapy. Anticancer Res. 24, 3161-3167.

Chen, J., Elfiky, A., Han, M., Chen, C., Saif, M.W., 2014. The role of src in colon cancer and its therapeutic implications. Clin. Colorectal Canc. 13, 5-13. https://doi.org/10. 1016/j.clcc.2013.10.003.

Chen, J., Smith, M., Kolinsky, K., Adames, V., Mehta, N., Fritzky, L., Rashed, M., Wheeldon, E., Linn, M., Higgins, B., 2007. Antitumor activity of HER1/EGFR tyrosine kinase inhibitor erlotinib, alone and in combination with CPT-11 (irinotecan) in human colorectal cancer xenograft models. Canc. Chemother. Pharmacol. 59, 651-659. https://doi.org/10.1007/s00280-006-0320-8.

Cheruku, H.R., Mohamedali, A., Cantor, D.I., Tan, S.H., Nice, E.C., Baker, M.S., 2015. Transforming growth factor- $\beta$, MAPK and Wnt signaling interactions in colorectal cancer. EuPA Open Proteomics 8, 104-115. https://doi.org/10.1016/j.euprot.2015. 06.004.

Cui, Y., Sun, Y., Hu, S., Luo, J., Li, L., Li, X., Yeh, S., Jin, J., Chang, C., 2016. Neuroendocrine prostate cancer (NEPCa) increased the neighboring PCa chemoresistance via altering the $\mathrm{PTHrP} / \mathrm{p} 38 / \mathrm{Hsp} 27 /$ androgen receptor (AR)/p21 signals. Oncogene 35, 6065-6076. https://doi.org/10.1038/onc.2016.135.

de Weger, V.A., Beijnen, J.H., Schellens, J.H., 2014. Cellular and clinical pharmacology of the taxanes docetaxel and paclitaxel-a review. Anti Canc. Drugs 25 (5), 488-494. https://doi.org/10.1097/CAD.0000000000000093.

Ebi, H., Costa, C., Faber, A.C., Nishtala, M., Kotani, H., Juric, D., Della Pelle, P., Song, Y., Yano, S., Mino-Kenudson, M., Benes, C.H., Engelman, J.A., 2013. PI3K regulates MEK/ERK signaling in breast cancer via the Rac-GEF, P-Rex1. Proc. Natl. Acad. Sci. Unit. States Am. 110, 21124-21129. https://doi.org/10.1073/pnas.1314124110.

El Khoury, F., Corcos, L., Durand, S., Simon, B., Le Jossic-Corcos, C., 2016. Acquisition of anticancer drug resistance is partially associated with cancer stemness in human colon cancer cells. Int. J. Oncol. 49, 2558-2568. https://doi.org/10.3892/ijo.2016. 3725 .

Erdem, Z.N., Schwarz, S., Drev, D., Heinzle, C., Reti, A., Heffeter, P., Hudec, X., Holzmann, K., Grasl-Kraupp, B., Berger, W., Grusch, M., Marian, B., 2017. Irinotecan upregulates fibroblast growth factor receptor 3 expression in colorectal cancer cells, which mitigates irinotecan-induced apoptosis. Transl. Oncol. 10, 332-339. https:// doi.org/10.1016/j.tranon.2017.02.004

Frame, M.C., 2004. Newest findings on the oldest oncogene; how activated src does it. J. Cell Sci. 117, 989-998. https://doi.org/10.1242/jcs.01111.

Frolik, C.A., Cain, R.L., Sato, M., Harvey, A.K., Chandrasekhar, S., Black, E.C., Tashjian Jr., A.H., Hock, J.M., 1999. Comparison of recombinant human PTH(1-34) (LY333334) with a C-terminally substituted analog of human PTH-related protein(134) (RS-66271): in vitro activity and in vivo pharmacological effects in rats. J. Bone Miner. Res. 14 (2), 163-172. https://doi.org/10.1359/jbmr.1999.14.2.163.

Gagiannis, S., Müller, M., Uhlemann, S., Koch, A., Melino, G., Krammer, P.H., Nawroth, P.P., Brune, M., Schilling, T., 2009. Parathyroid hormone-related protein confers chemoresistance by blocking apoptosis signaling via death receptors and mitochondria. Int. J. Canc. 125, 1551-1557. https://doi.org/10.1002/ijc.24471.

Galindo, R.J., Romao, I., Valsamis, A., Weinerman, S., Harris, Y.T., 2016. Hypercalcemia of malignancy and colorectal cancer. World J. Oncol. 7 (1), 5-12. https://doi.org/10. 14740/wjon953w.

Garg, R., Benedetti, L.G., Abera, M.B., Wang, H., Abba, M., Kazanietz, M.G., 2014. Protein kinase C and cancer: what we know and what we do not. Oncogene 33 (45), 5225-5237. https://doi.org/10.1038/onc.2013.524.

Greco, S., Storelli, C., Marsigliante, S., 2006. Protein kinase C (PKC)- $\delta /-\varepsilon$ mediate the PKC/Akt-dependent phosphorylation of extracellular signal-regulated kinases 1 and 2 in MCF-7 cells stimulated by bradykinin. J. Endocrinol. 188, 79-89. https://doi.org/ 10.1677/joe.1.06433.

Guglielmi, A.P., Sobrero, A.F., 2007. Second-line therapy for advanced colorectal cancer. Gastrointest Cancer Res 1, 57-63.

Hammond, W.A., Swaika, A., Mody, K., 2016. Pharmacologic resistance in colorectal cancer: a review. Ther Adv Med Oncol 8, 57-84. https://doi.org/10.1177/ 1758834015614530.

Ilyas, M., Tomlinson, I.P., Rowan, A., Pignatelli, M., Bodmer, W.F., 1997. Beta-catenin mutations in cell lines established from human colorectal cancers. Proc. Natl. Acad. Sci. U. S. A. 16;94 (19), 10330-10334.

Irby, R.B., Yeatman, T.J., 2000. Role of Src expression and activation in human cancer Oncogene 19, 5636-5642. https://doi.org/10.1038/sj.onc.1203912.

Kang, J.H., 2014. Protein kinase C (PKC) isozymes and cancer. New Sci. Sci. J. 2014, 1-36. https://doi.org/10.1155/2014/231418.
Khaleghpour, K., 2004. Involvement of the PI 3-kinase signaling pathway in progression of colon adenocarcinoma. Carcinogenesis 25, 241-248. https://doi.org/10.1093/ carcin/bgg195.

Kir, S., White, J.P., Kleiner, S., Kazak, L., Cohen, P., Baracos, V.E., Spiegelman, B.M., 2014. Tumour-derived PTH-related protein triggers adipose tissue browning and cancer cachexia. Nature 513, 100-104. https://doi.org/10.1038/nature13528.

Kovacs, C.S., 2015. Calcium, phosphorus, and bone metabolism in the fetus and newborn. Early Hum. Dev. 91, 623-628. https://doi.org/10.1016/j.earlhumdev.2015.08.007.

Lemieux, E., Cagnol, S., Beaudry, K., Carrier, J., Rivard, N., 2015. Oncogenic KRAS signalling promotes the Wnt/ $\beta$-catenin pathway through LRP6 in colorectal cancer. Oncogene 34, 4914-4927. https://doi.org/10.1038/onc.2014.416.

Levy, D.S., Kahana, J.A., Kumar, R., 2009. AKT inhibitor, GSK690693, induces growth inhibition and apoptosis in acute lymphoblastic leukemia cell lines. Blood 113, 1723-1729. https://doi.org/10.1182/blood-2008-02-137737.

Lezcano, V., Gentili, C., de Boland, A.R., 2013. Role of PTHrP in human intestinal Caco-2 cell response to oxidative stress. Biochim. Biophys. Acta Mol. Cell Res. 1833, 2834-2843. https://doi.org/10.1016/j.bbamcr.2013.06.029.

Li, H., Seitz, P.K., Thomas, M.L., Selvanayagam, P., Rajaraman, S., Cooper, C.W., 1995. Widespread expression of the parathyroid hormone-related peptide and PTH/PTHrP receptor genes in intestinal epithelial cells. Lab. Invest. 73, 864-870.

Lieu, C., Kopetz, S., 2010. The Src family of protein tyrosine kinases: a new and promising target for colorectal cancer therapy. Clin. Colorectal Cancer 9 (2), 89-94. https://doi. org/10.3816/CCC.2010.n.012.

Luna-Ulloa, L.B., Hernandez-Maqueda JG,Santoyo-Ramos, P., Castañeda-Patlán, M.C., Robles-Flores, M., 2011. Protein kinase $\mathrm{C} \zeta$ is a positive modulator of canonical Wnt signaling pathway in tumoral colon cell lines. Carcinogenesis 32 (11), 1615-1624. https://doi.org/10.1093/carcin/bgr190.

Maat, W., Filali, M el, Mulder, A.D., Luyten, G.P.M., Gruis, N.A., Desjardins, L., Boender, P., Jager, M.J., van der Velden, P.A., 2009. Episodic Src activation in uveal melanoma revealed by kinase activity profiling. Br. J. Canc. 101, 312-319. https://doi.org/10. 1038/sj.bjc.6605172.

Maioli, E., Fortino, V., 2004. The complexity of parathyroid hormone-related protein signalling. Cell. Mol. Life Sci. 61, 257-262. https://doi.org/10.1007/s00018-0033233-2.

Maitra, R., Seetharam, R., Tesfa, L., Augustine, T.A., Klampfer, L., Coffey, M.C., Mariadason, J.M., Goel, S., 2014. Oncolytic reovirus preferentially induces apoptosis in KRAS mutant colorectal cancer cells, and synergizes with irinotecan. Oncotarget 5 , 2807-2819. https://doi.org/10.18632/oncotarget.1921.

Malakouti, S., Asadi, F.K., Kukreja, S.C., Abcarian, H.A., Cintron, J.R., 1996. Parathyroid hormone-related protein expression in the human colon: immunohistochemical evaluation. Am. Surg. 62, 540-544 discussion 544-545.

Marengo, B., De Ciucis, C., Ricciarelli, R., Pronzato, M., Marinari, U., Domenicotti, C., 2011. Protein kinase C: an attractive target for cancer therapy. Cancers 3, 531-567. https://doi.org/10.3390/cancers3010531.

Martín, M.J., Calvo, N., de Boland, A.R., Gentili, C., 2014. Molecular mechanisms associated with PTHrP-induced proliferation of colon cancer cells. J. Cell. Biochem. 115, 2133-2145. https://doi.org/10.1002/jcb.24890.

Masur, K., Lang, K., Niggemann, B., Zanker, K.S., Entschladen, F., 2001. High PKC $\alpha$ and low E-cadherin expression contribute to high migratory activity of colon carcinoma cells. Mol. Biol. Cell 12 (7), 1973-1982. https://doi.org/10.1091/mbc.12.7.1973.

McCauley, L.K., Martin, T.J., 2012. Twenty-five years of PTHrP progress: from cancer hormone to multifunctional cytokine. J. Bone Miner. Res. 27, 1231-1239. https:// doi.org/10.1002/jbmr.1617.

McCubrey, J.A., Steelman, L.S., Chappell, W.H., Abrams, S.L., Wong, E.W.T., Chang, F., Lehmann, B., Terrian, D.M., Milella, M., Tafuri, A., Stivala, F., Libra, M., Basecke, J., Evangelisti, C., Martelli, A.M., Franklin, R.A., 2007. Roles of the Raf/MEK/ERK pathway in cell growth, malignant transformation and drug resistance. Biochim. Biophys. Acta Mol. Cell Res. 1773, 1263-1284. https://doi.org/10.1016/j.bbamcr 2006.10.001.

McIntyre, R.E., Buczacki, S.J.A., Arends, M.J., Adams, D.J., 2015. Mouse models of colorectal cancer as preclinical models. Bioessays 37, 909-920. https://doi.org/10. 1002/bies. 201500032.

McKinley, E.T., Liu, H., McDonald, W.H., Luo, W., Zhao, P., Coffey, R.J., Hanks, S.K., Manning, H.C., 2013. Global phosphotyrosine proteomics identifies PKC $\delta$ as a marker of responsiveness to src inhibition in colorectal cancer. PLoS One 8, e80207. https:// doi.org/10.1371/journal.pone.0080207.

Mocellin, S., Baretta, Z., M, R.F., Solà, I., Hallum, S., X, B.C., 2017. Second-line systemic therapy for metastatic colorectal cancer ( Review ). Cochrane Database Syst. Rev. https://doi.org/10.1002/14651858.CD006875.pub3.www.cochranelibrary.com.

Nishihara, M., Ito, M., Tomioka, T., Ohtsuru, A., Taguchi, T., Kanematsu, T., 1999. Clinicopathological implications of parathyroid hormone-related protein in human colorectal tumours. J. Pathol. 187 (2), 217-222. https://doi.org/10.1002/(SICI) 1096-9896(199901)187 $2<217:$ :AID-PATH210 > 3.0.CO;2-0.

Nishihara, M., Kanematz, T., Taguchi, T., Razzaque, M.S., 2007. PTHrP and tumorigenesis: is there a role in prognosis? Ann. N. Y. Acad. Sci. 1117 (1), 385-392. https://doi org/10.1196/annals.1402.046.

Paillas, S., Boissiere, F., Bibeau, F., Denouel, A., Mollevi, C., Causse, A., Denis, V., VezzioVie, N., Marzi, L., Cortijo, C., Ait-Arsa, I., Askari, N., Pourquier, P., Martineau, P., Del Rio, M., Gongora, C., 2011. Targeting the p38 MAPK pathway inhibits irinotecan resistance in colon adenocarcinoma. Canc. Res. 71, 1041-1049. https://doi.org/10. 1158/0008-5472.CAN-10-2726.

Pandurangan, A.K., 2013. Potential targets for prevention of colorectal cancer: a focus on PI3K/Akt/mTOR and Wnt pathways. Asian Pac. J. Cancer Prev. APJCP 14, 2201-2205.

Park, Y.-S., Cho, N.J., 2012. EGFR and PKC are involved in the activation of ERK1/2 and p90 RSK and the subsequent proliferation of SNU-407 colon cancer cells by 
muscarinic acetylcholine receptors. Mol. Cell. Biochem. 370, 191-198. https://doi. org/10.1007/s11010-012-1410-Z.

Peng, H., Dara, L., Li, T.W.H., Zheng, Y., Yang, H., Tomasi, M.L., Tomasi, I., Giordano, P., Mato, J.M., Lu, S.C., 2013. MAT2B-GIT1 interplay activates MEK1/ERK 1 and 2 to induce growth in human liver and colon cancer. Hepatology 57, 2299-2313. https:// doi.org/10.1002/hep.26258.

Plotnikov, A., Zehorai, E., Procaccia, S., Seger, R., 2011. The MAPK cascades: signaling components, nuclear roles and mechanisms of nuclear translocation. Biochim. Biophys. Acta Mol. Cell Res. 1813, 1619-1633. https://doi.org/10.1016/j.bbamcr. 2010.12.012.

Pysz, M.A., Hao, F., Hizli, A.A., Lum, M.A., Swetzig, W.M., Black, A.R., Black, J.D., 2014. Differential regulation of cyclin D1 expression by protein kinase C and signaling in intestinal epithelial cells. J. Biol. Chem. 289, 22268-22283. https://doi.org/10. 1074/jbc.M114.571554.

Saksena, S., Gill, R.K., Tyagi, S., Alrefai, W.A., Sarwar, Z., Ramaswamy, K., Dudeja, P.K., 2005. Involvement of $\mathrm{c}$-src and protein kinase $\mathrm{C}$ in the inhibition of $\mathrm{Cl}-\mathrm{OOH}$ - exchange activity in Caco-2 cells by serotonin. J. Biol. Chem. 280, 11859-11868. https://doi. org/10.1074/jbc.M411553200.

Samatar, A.A., Poulikakos, P.I., 2014. Targeting RAS-ERK signalling in cancer: promises and challenges. Nat. Rev. Drug Discov. 13, 928-942. https://doi.org/10.1038/ nrd4281.

Scaglione-Sewell, B., Abraham, C., Bissonnette, M., Skarosi, S.F., Hart, J., Davidson, N.O., Wali, R.K., Davis, B.H., Sitrin, M., Brasitus, T.A., 1998. Decreased PKC-alpha expression increases cellular proliferation, decreases differentiation, and enhances the transformed phenotype of CaCo-2 cells. Cancer Res. 58 (5), 1074-1081.

Setia, S., Nehru, B., Sanyal, S.N., 2014. Upregulation of MAPK/Erk and PI3K/Akt pathways in ulcerative colitis-associated colon cancer. Biomed. Pharmacother. 68, 1023-1029. https://doi.org/10.1016/j.biopha.2014.09.006.

Shen, X., Rychahou, P.G., Evers, B.M., Falzon, M., 2007. PTHrP increases xenograft growth and promotes integrin $\alpha 6 \beta 4$ expression and Akt activation in colon cancer. Canc. Lett. 258, 241-252. https://doi.org/10.1016/j.canlet.2007.09.010.

Sidler, B., Alpert, L., Henderson, J.E., Deckelbaum, R., Amizuka, N., Silva, J.E., Goltzman, D., Karaplis, A.C., 1996. Amplification of the parathyroid hormone-related peptide gene in a colonic carcinoma. J. Clin. Endocrinol. Metab. 81 (8), 2841-2847.

Siegel, R.L., Miller, K.D., Jemal, A., 2015. Cancer statistics, 2015. CA A Cancer J. Clin. 65, 5-29. https://doi.org/10.3322/caac.21254.

Soki, F.N., Park, S.I., McCauley, L.K., 2012. The multifaceted actions of PTHrP in skeletal metastasis. Future Oncol. 8, 803-817. https://doi.org/10.2217/fon.12.76.

Steelman, L.S., Chappell, W.H., Abrams, S.L., Kempf, C.R., Long, J., Laidler, P., Mijatovic, S., Maksimovic-Ivanic, D., Stivala, F., Mazzarino, M.C., Donia, M., Fagone, P., Malaponte, G., Nicoletti, F., Libra, M., Milella, M., Tafuri, A., Bonati, A., Bäsecke, J., Cocco, L., Evangelisti, C., Martelli, A.M., Montalto, G., Cervello, M., McCubrey, J.A., 2011. Roles of the Raf/MEK/ERK and PI3K/PTEN/Akt/mTOR pathways in controlling growth and sensitivity to therapy-implications for cancer and aging. Aging (N Y) 3, 192-222. https://doi.org/10.18632/aging.100296.

Stewart, A.F., Cain, R.L., Burr, D.B., Jacob, D., Turner, C.H., Hock, J.M., Drezner, M.K., 2000. Six-month daily administration of parathyroid hormone and parathyroid hormone-related protein peptides to adult ovariectomized rats markedly enhances bone mass and biomechanical properties: a comparison of human parathyroid hormone 1 -
34, parathyroid hormo. J. Bone Miner. Res. 15, 1517-1525. https://doi.org/10. 1359/jbmr.2000.15.8.1517.

Tan, X., Chen, S., Wu, J., Lin, J., Pan, C., Ying, X., Pan, Z., Qiu, L., Liu, R., Geng, R., Huang, W., 2017. PI3K/AKT-mediated upregulation of WDR5 promotes colorectal cancer metastasis by directly targeting ZNF407. Cell Death Dis. 8 e2686-e2686. https://doi.org/10.1038/cddis.2017.111.

Terraneo, L., Avagliano, L., Caretti, A., Bianciardi, P., Tosi, D., Bulfamante, G.P., Samaja, M., Trinchera, M., 2013. Expression of carbohydrate-antigen sialyl-Lewis a on colon cancer cells promotes xenograft growth and angiogenesis in nude mice. Int. J. Biochem. Cell Biol. 45 (12), 2796-2800. https://doi.org/10.1016/j.biocel.2013.10. 003.

Tong, Y., Yang, W., Koeffler, H.P., 2011. Mouse models of colorectal cancer. Chin. J. Canc. 30, 450-462. https://doi.org/10.5732/cjc.011.10041.

Vivanco, I., Sawyers, C.L., 2002. The phosphatidylinositol 3-Kinase-AKT pathway in human cancer. Nat. Rev. Canc. 2, 489-501. https://doi.org/10.1038/nrc839.

Wang, Q., Li, N., Wang, X., Kim, M.M., Evers, B.M., 2002. Augmentation of sodium butyrate-induced apoptosis by phosphatidylinositol 3'-kinase inhibition in the KM20 human colon cancer cell line. Clin. Canc. Res. 8, 1940-1947.

Watson, P.H., Fraher, L.J., Hendy, G.N., Chung, U.I., Kisiel, M., Natale, B.V., Hodsman, A.B., 2000. Nuclear localization of the type $1 \mathrm{PTH} / \mathrm{PTHrP}$ receptor in rat tissues. J. Bone Miner. Res. 15 (6), 1033-1044. https://doi.org/10.1359/jbmr.2000.15.6.1033.

Wooten, M.W., Vandenplas, M.L., Seibenhener, M.L., Geetha, T., Diaz-Meco, M.T., 2001. Nerve growth factor stimulates multisite tyrosine phosphorylation and activation of the atypical protein kinase C's via a src kinase pathway. Mol. Cell Biol. 21 , 8414-8427. https://doi.org/10.1128/MCB.21.24.8414-8427.2001.

Wu, B., Zhou, H., Hu, L., Mu, Y., Wu, Y., 2013. Involvement of PKC $\alpha$ activation in TF/ VIIa/PAR2-induced proliferation, migration, and survival of colon cancer cell SW620. Tumor Biol. 34, 837-846. https://doi.org/10.1007/s13277-012-0614-x.

Wysolmerski, J.J., Stewart, A.F., 1998. The physiology of parathyroid hormone-related protein: an emerging role as a developmental factor. Annu. Rev. Physiol. 60, 431-460. https://doi.org/10.1146/annurev.physiol.60.1.431.

Wysolmerski, J.J., 2012. Parathyroid hormone-related protein: an update. J. Clin. Endocrinol. Metab. 97, 2947-2956. https://doi.org/10.1210/jc.2012-2142.

Yang, K., Gao, K., Hu, G., Wen, Y., Lin, C., Li, X., 2016a. CTGF enhances resistance to 5FU-mediating cell apoptosis through FAK/MEK/ERK signal pathway in colorectal cancer. Onco Targets Ther Volume 9, 7285-7295. https://doi.org/10.2147/OTT. S108929.

Yang, P., Wang, J., Wang, Y., Jan, W., Cheng, S., Hsu, Y., 2016b. 1,6-Bis[4-(4-amino-3hydroxyphenoxy)phenyl] diamantane potentiates in vitro and in vivo antitumor effects of irinotecan on human colorectal cancer cells. Oncol Lett. https://doi.org/10. 3892/ol.2016.4430.

Yang, H., Lin, M., Xiong, F.X., Nie, Y., Zhou, X.L.R., 2010. Reduced expression of ASS is closely related to clinicopathological features and post-resectional survival of hepatocellular carcinoma. Oncol Lett 1. https://doi.org/10.3892/ol 00000005.

Zhou, H., Klein, A.L., Lu, S.S., Ducayen-Knowles, M., Levine, L.R., Dempster, D.W., Lindsay, R., 2003. Anabolic action of parathyroid hormone on cortical and cancellous bone differs between axial and appendicular skeletal sites in mice. Bone 32 (5), 513-520. https://doi.org/10.1016/S8756-3282(03) 00057-7. 